\title{
Polylactic Acid Piezo-Biopolymers: Chemistry, Structural Evolution, Fabrication Methods, and Tissue Engineering Applications
}

\author{
Amirhossein Farahani ${ }^{1, *}$, Abbas Zarei-Hanzaki ${ }^{1, *}$, Hamid Reza Abedi ${ }^{2, *(D,}$, Lobat Tayebi 3 \\ and Ebrahim Mostafavi $4,5, *$ (D)
}

1 Hot Deformation \& Thermomechanical Processing Laboratory of High Performance Engineering Materials, School of Metallurgy and Materials Engineering, College of Engineering, University of Tehran, Tehran 11155-4563, Iran

2 School of Metallurgy \& Materials Engineering, Iran University of Science and Technology (IUST), Tehran 16846-13114, Iran

3 School of Dentistry, Marquette University, Milwaukee, WI 53233, USA; lobat.tayebi@marquette.edu

4 Stanford Cardiovascular Institute, Stanford University School of Medicine, Stanford, CA 94305, USA

5 Department of Medicine, Stanford University School of Medicine, Stanford, CA 94305, USA

* Correspondence: Amirhsfarahanii@ut.ac.ir (A.F.); zareih@ut.ac.ir (A.Z.-H.); habedi@iust.ac.ir (H.R.A.); ebimsv@stanford.edu or ebi.mostafavi@gmail.com (E.M.)

\section{check for}

updates

Citation: Farahani, A.;

Zarei-Hanzaki, A.; Abedi, H.R.;

Tayebi, L.; Mostafavi, E. Polylactic Acid Piezo-Biopolymers: Chemistry, Structural Evolution, Fabrication Methods, and Tissue Engineering Applications. J. Funct. Biomater. 2021, 12, 71. https://doi.org/10.3390/ jfb12040071

Academic Editor:

Jarosław Jakubowicz

Received: 25 August 2021

Accepted: 18 November 2021

Published: 8 December 2021

Publisher's Note: MDPI stays neutral with regard to jurisdictional claims in published maps and institutional affiliations.

Copyright: (c) 2021 by the authors. Licensee MDPI, Basel, Switzerland. This article is an open access article distributed under the terms and conditions of the Creative Commons Attribution (CC BY) license (https:/ / creativecommons.org/licenses/by/ $4.0 /)$.
Abstract: Polylactide acid (PLA), as an FDA-approved biomaterial, has been widely applied due to its unique merits, such as its biocompatibility, biodegradability, and piezoelectricity. Numerous utilizations, including sensors, actuators, and bio-application-its most exciting application to promote cell migration, differentiation, growth, and protein-surface interaction-originate from the piezoelectricity effect. Since PLA exhibits piezoelectricity in both crystalline structure and an amorphous state, it is crucial to study it closely to understand the source of such a phenomenon. In this respect, in the current study, we first reviewed the methods promoting piezoelectricity. The present work is a comprehensive review that was conducted to promote the low piezoelectric constant of PLA in numerous procedures. In this respect, its chemistry and structural origins have been explored in detail. Combining any other variables to induce a specific application or to improve any PLA barriers, namely, its hydrophobicity, poor electrical conductivity, or the tuning of its mechanical properties, especially in the application of cardiovascular tissue engineering, is also discussed wherever relevant.

Keywords: polylactic acid (PLA); piezoelectric; crystalline structural evolution; texture; tissue engineering; thermomechanical process

\section{Introduction}

Active materials, intelligent or smart materials, and adaptive materials all have similar definitions in that the materials are capable of utilizing one or more properties together in response to an externally applied stimulator. The most popular are shape memory alloys, electrostrictive and magnetostrictive materials, optical fibers, electro-rheological materials, and piezoelectrics.

The word piezoelectricity (PE) is derived from the Greek word meaning pressure electricity. Because of a wide bandwidth, a fast electrochemical response, low power requirements, and high generative forces, PE materials are among the most widely used smart materials. The subset of PE is pyroelectricity; ferroelectricity is a property of certain dielectrics that exhibit polarization from themselves, which is directionally reversible by applying an appropriate electric field. The origin of ferroelectricity is the division of the positive and negative charges into two poles and the non-neutralization of the total charge. 
In recent years, however, researchers have explored the possibility of ferroelectricity in amorphous materials such as polymers.

PE materials have been popularly studied—but not wholly inspected-for energy harvesting, power generation, actuators, speakers, strain sensors [1], touch panels, screen instruments, and so on. PE is defined as the generation of electricity as a result of applying mechanical stress [2]. Electric fields are created without an external power source in piezo materials; nevertheless, control of the stimulation barriers is relevant in this field of research. Various therapy approaches, such as doctoring medicines, microfracture methods, allografting, and autografting, have been utilized to recover damaged tissue such as cartilage. Although these treatments aid in regenerating damaged cartilage tissue, restrictions also accompany them in most cases. Doctoring medicines require lasting rehabilitation, and the reconstruction of damaged tissue to its normal function is only partially possible [3]. The microfracture method has the potential to extract the subchondral bone marrow ancestor cells and repair the injuries, yet it is only suitable for minor injuries [4]. While maintaining all the mentioned positive results, TE has been used and demonstrated as an alternative approach to address these treatments' limitations [5-9].

One of the novel solutions of TE is the use of scaffolding to overcome the imperfection of living tissues. A scaffold is a medium with which to culture cells to provide the growth factors [10]. The tissue repair and regeneration processes necessitate multiple steps that work together to ensure operative recoveries, such as between electricity propagation and mechanical pulses. Because of the physiological movements inside the body, scaffolds fabricated from PE material actuates are attractive choices to convert mechanical movements into electrical stimulation and vice versa. Countless hybrid and singular structures have been identified as efficient scaffolds for naive cell growth. Among them, materials with piezoelectric properties have significant potential for TE and regeneration.

The implementation of PE materials into TE has provided a wide range of applications, namely, the blood-brain barrier, drug delivery, cancer treatments, cartilage [11], TE, dental applications [12], fixation implants, and bone screws. Other stabilization tools, such as pins, washers, and darts [13], as well as nerve applications [14], skeletal muscle [15], and cardiac tissue engineering (TE) [16] are mentioned in the literature.

Researchers have been trying to find a sustainable energy source using triboelectricity, $\mathrm{PE}$, and electromagnetics. PE generators are studied more often because of their excellent electromechanical properties. There are two types of PE materials-one is based on ceramics, and the other is polymer-based. Ceramic materials have a high PE constant, but they are brittle and lack ductility, while polymer PE materials are flexible with good durability but a low PE constant [17]. In this regard, the most known piezo polymer is PVDF and its copolymer, which has high chemical resistance and high PE properties and is biocompatible, lightweight, and flexible.

In biomedical applications, some essential parameters should be available to support the use of PE materials, for instance, mechanical interactions between cells and the material surface caused by cell adhesion, motility, cytoskeletal organization, cell migration, differentiation, and morphogenesis of tissue [18]. Several studies have shown that some cell lines require external stimuli to improve tissue repair, which is why the use of electro/mechanically active materials is increasingly gaining attention. Micro- and nanotechnologies have been used to help produce TE scaffolds and to provide more suitable environments for tissues to potentially regenerate by controlling the morphology and chemistry at the micro- and nanoscales. Other studies have shown that some cell lines, such as osteoblasts and chondrocytes, depend on external stimuli (mechanical or electrical) for enhanced tissue repair. Indeed, TE has also been used with active materials, such as conducting polymers and PE materials, to fabricate optimal scaffolds for specific applications. 


\section{Piezoelectricity in Polymers}

\subsection{The Origin of Piezoelectricity and Its Categorization}

In 1880, the Curie brothers ascertained that when pressure is applied to quartz crystals and Rochelle salt, an electrical charge generates on the surfaces of these materials $[19,20]$. This discovery was a milestone in material science and engineering. Two different but related responses are possible with PE materials—direct and reverse piezoelectricity (PE). With applied mechanical stress, the response is direct. PE occurs when a dielectric material produces an electrical charge across its boundaries. Indirect or inverse PE occurs when the material shrinks or expands due to the employed electrical charge [2]. This property can be understood with the help of what is defined as a crystalline structure in material science and engineering- $\mathrm{PE}$ results from the non-inverse symmetric structure arrangement of the ions in a dielectric material [21].

There are two different types of PE-normal and shear. Normal PE is attributed to the materials that respond to the applied force directly. When the structure deforms in the $X, Y$, or $\mathrm{Z}$ directions, the electrical charge accumulates on one of the mentioned directions of the specimen. When an excitation charge is applied to the sample, volume accretion emerges in the same way. The shear PE definition is the material's structural twist in response to the electrical stimulation [22]. A complete comprehensive schematic that illustrates PE is presented in Figure 1.

(a)

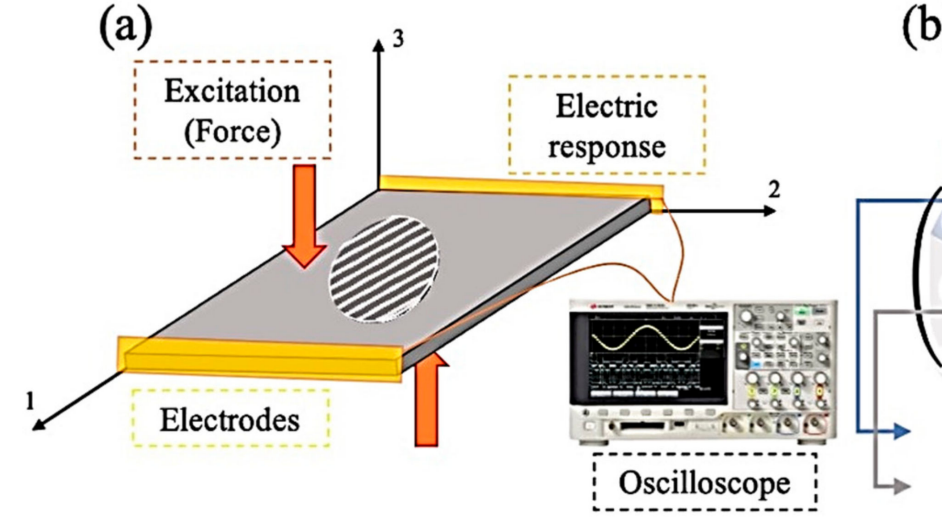

(c) (b)

(d)

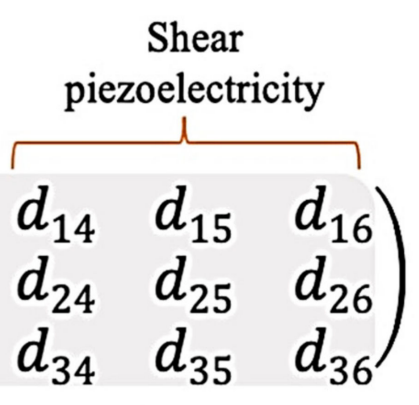

Longitudinal Piezoelectric strain coefficient

Transverse Piezoelectric strain coefficient

(e)

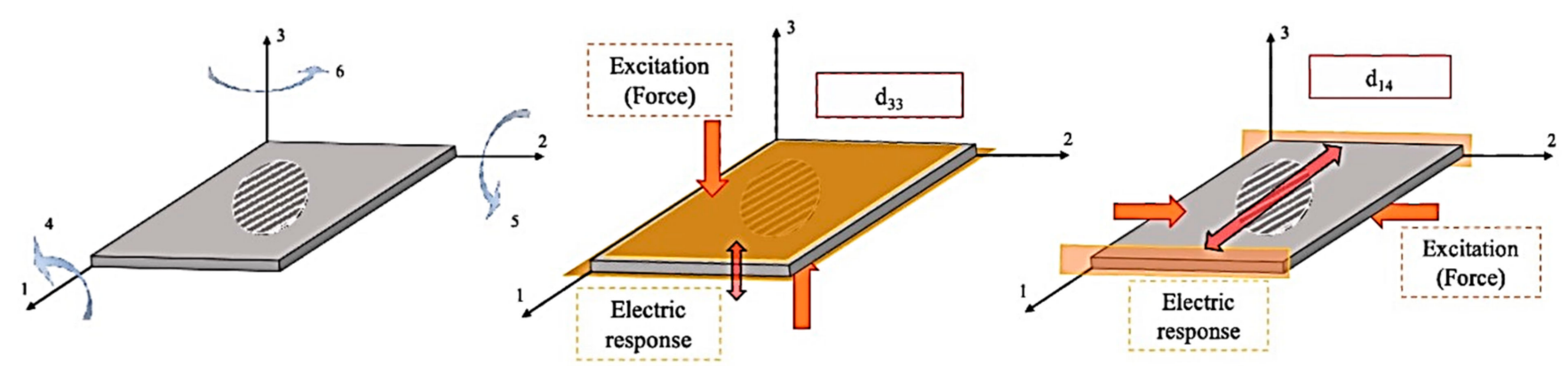

Figure 1. (a,c) Relationship between applied normal $(\sigma)$ and shear $(\tau)$ stress and corresponding induced electric field $(E)$, (b) piezoelectricity matrix, (d) $\mathrm{d}_{33}$ as an example of normal-longitudinal PE response, (e) $\mathrm{d}_{14}$ as an example of normallongitudinal PE response.

\subsection{Ferro/Piezoelectricity in Semi-Crystalline Polymers}

PE's source in semicrystalline polymers becomes crystal clear when the focus is concentrated on the matter of polar domains in crystalline or amorphous regions. In such polymers, crystalline regions are dispersed in the amorphous matrix; this amorphous region has a glass transition temperature affecting the polymer's mechanical properties; as a matter of fact, as the material's $T_{g}$ decreases, the elastic chains sliding over each other 
would be easier, and on the other hand, in the crystalline regions, the chain sliding is more complicated due to the newly ordered phases [23]. The degree of crystallinity in this type of material depends on its thermal history and method of preparation.

Several polymorphic phases come into account, which can be developed as a function of the crystallization conditions, focusing on semicrystalline polymers. It is noteworthy that not all of these phases are polar or thermodynamically stable, which is crucial when looking for stabilized piezoelectric material. Inducing a crystalline phase transformation, mechanical orientation, thermal annealing, and high voltage treatment are some methods that have a practical corollary [24].

Levo, a derivative of Chiral PLA Biopolymer, poly-L-lactide (PLLA) with 37\% crystallinity, is reported for its high $\mathrm{PE} \mathrm{d}_{14}=-10 \mathrm{pC} / \mathrm{N}$ constant [25]. Another study reports the $d_{33}$ value of PLLA as 7-12 pC/N (smaller than PZT) and dielectric constant 2.5, making large PE output constant roughly similar to that of PVDF (both $\mathrm{d}_{33}$ and dielectric constants are high in this case). This advantage of the shear PE of PLA is applied in developing sensors as well [26].

Fundamentally, stretching the polymer aligns the amorphous strands in the film plane and aids in the consistent and uniform rotation of the crystallites by an electric field. The stretching will either be uniaxial or biaxial, so depending on this stretching, the electrical and mechanical properties will be either highly anisotropic or isotropic in the plane of the polymer sheet. Polymer poling can be accomplished using a direct contact method or a corona discharge. In this way, one of the popular methods is electrospinning (ES). During the ES process, fast evaporation of the solvent creates an amorphous structure of oriented fibers; it is much easier to increase the crystallinity by the hot drawing process. Surface area intensification, resulting from lower-diameter or more rough fibers, slightly decreases the glass transition and melting temperatures [27].

\subsection{Ferroelectricity and Piezoelectricity}

Although all piezoelectric materials are ferroelectric, not all ferroelectric materials are piezoelectric. Considering this issue, PVDF follows both piezoelectric and ferroelectric states, while PLA tends to be just a piezoelectric material lacking the ferroelectricity property. By applying a high electric field to semicrystalline polymers, for instance, PVDF polarization occurs nonlinearly, defined as a hysteresis loop. The proof of ferroelectricity is the reversal and spontaneous polarization. In this type of material, the quantity of the coercive field and the remanent polarization have to be adverted [28].

Inducing the PE to such ferroelectric polymers is governed by applying a high electric field during the fabrication method. This biased fabrication barrier is because the applied electric field should be near the permanent remanence, $P_{r}$, to align the dipole domains, in PVDF case; $\mathrm{C}=\mathrm{F}$ dipoles [29].

In this regard, the Curie-temperature $T_{c}$ is close to the polymer's melting temperature but lower. Below $T_{c}$, the polymer is ferroelectric, and above $T_{c}$, its non-centrosymmetric structure is disrupted. Although the ferroelectric phenomenon has been well acknowledged in ceramic crystals, the question of whether polymer crystallites could exhibit dipole switching was the source of many discussions for about a decade following the discovery of PE in PVDF [30].

\section{Fabrication Methods}

Fabrication of electroactive biopolymers contains various procedures, each encompassing advantages, and disadvantages. Both 3D and 2D porous scaffolds include essential functions meant to provide porous structures that are desirable for cell accommodation and activity. Numerous procedures have been employed to adjust porous scaffolds, namely, phase separation [31], gas-forming [32], freeze-drying [33], solvent casting/particulate leaching $[34,35]$, and additive manufacturing [36].

These aforementioned methods possess problems related to the remaining toxic organic solvents, blocked pore structures, and unwanted skin layer formation. Even though 
the additive manufacturing technique can develop complex structures, it is not a costeffective method, and only limited materials can be used in this technique [37].

On one hand, well-controlled pore structures are required; while on the other hand, the tuned mechanical property is essential for maintaining essential cell proliferation and matrix secretion to regenerate new tissue. Natural polymer-based scaffolds, such as processed collagen and gelatin scaffolds, provide numerous benefits, including bioactivity and biocompatibility, while their poor mechanical properties still remain as weakness.

Obtaining porous scaffolds is possible with some methods, namely, solvent casting/salt leaching, phase separation, gas foaming, gel casting, precipitation, and emulsion freeze-drying [38]. On the other hand, significant restrictions follow these methods, such as the probability of creating scaffolds with an inaccurate or restricted interconnectivity pore morphology that is disadvantageous for identical cell seeding and tissue extension [39], and their insufficiency to cause PE characteristics in the material.

The most attractive method for fabricating porous tissue mimetic artificial patches is the ES method, thoroughly discussed [40]. Fabricating excellent isotropic mechanical properties in PLLA samples with mold-based methods, such as high-pressure molding, injection molding, and vacuum molding, is among the conventional methods because of the prohibition of aligned chains and not arising the PE PLLA samples [41]. It is also possible to use 3D printing's potential with molding methods [42]. In a study by Hayashi et al., they attempted to obtain orientated PLLA chains by optimizing the molding temperature and pressure to engender uniaxial-oriented molecular chains in a local area and promote PE [43].

Achieving nano/microfibrous structures mimicking the extracellular matrices (ECM) is an important consideration; several techniques have been introduced, namely, the selfassembly of peptide amphiphile, block copolymers, and dendrimers.

\subsection{Electrospinning Parameters}

Considering the technical issues, nanofibers with diameters between tens of nanometers to less than $1 \mu \mathrm{m}$ possess a high aspect ratio, which virtually leads to the definition of one-dimensional material. These peculiarities bring them unique properties, which are practical in various applications. Nanofibers are fabricated using numerous methods: wet-spinning [44], dry-spinning, or melt spinning [45,46]; template synthesis [47]; solution blow spinning [48]; and force spinning [49], to name a few. Still, the most prevalent highly effective procedure is the ES technique, i.e., the fabrication of nanofibers using electrostatic forces [50].

The process of ES (Figure 2) is essentially associated with its versatility; on the one hand, it is a mild and cost-effective manner, and on the other hand, the electrified polymeric jet develops instability and solidifies the fibers to design long, unbroken, and connected nanofibers with diameters differing from tens of nanometers to a few micrometers [51].

The physical and mechanical properties of the fibers can be varied as a function of different parameters such as solution concentration, solution feed rate, applied voltage, rate of needle movement, and the method of collection [52]. 
(a)

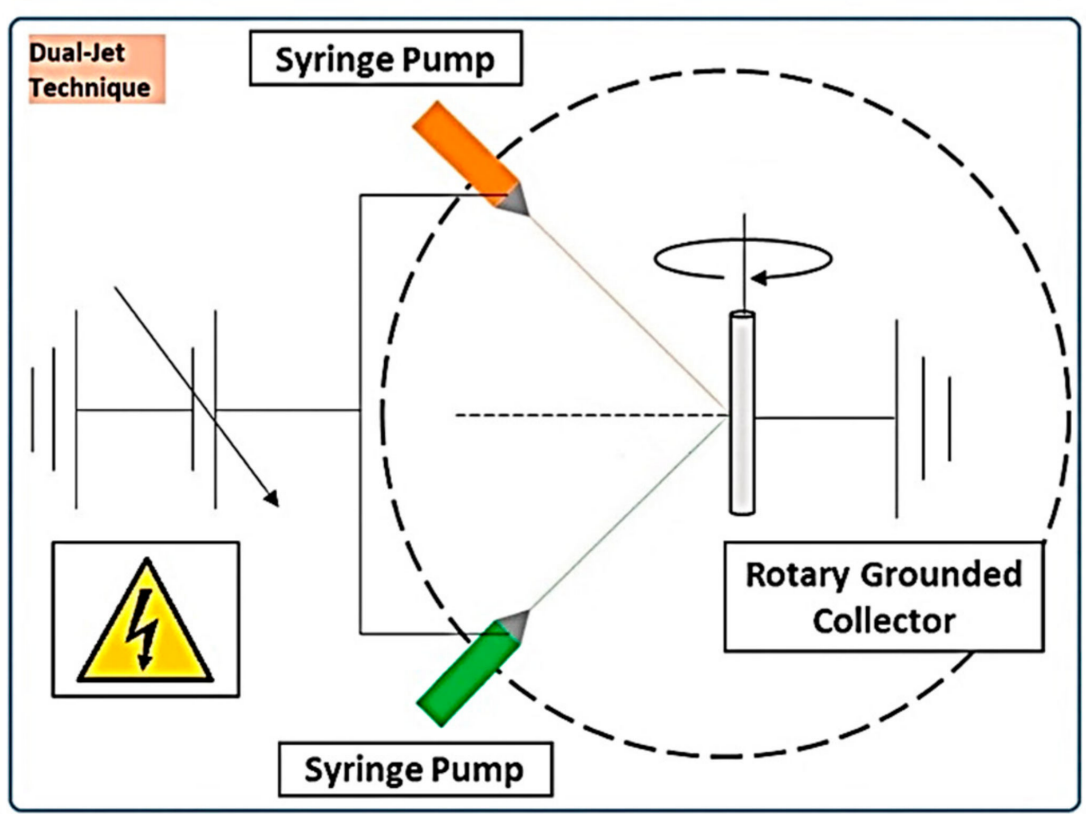

(b)

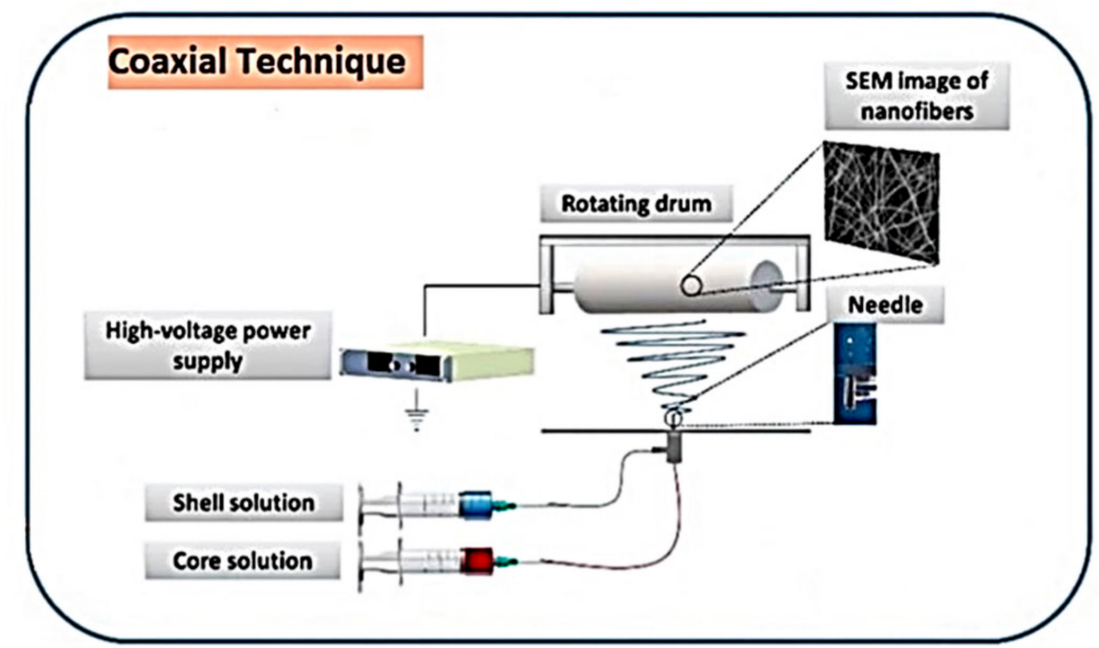

(c)

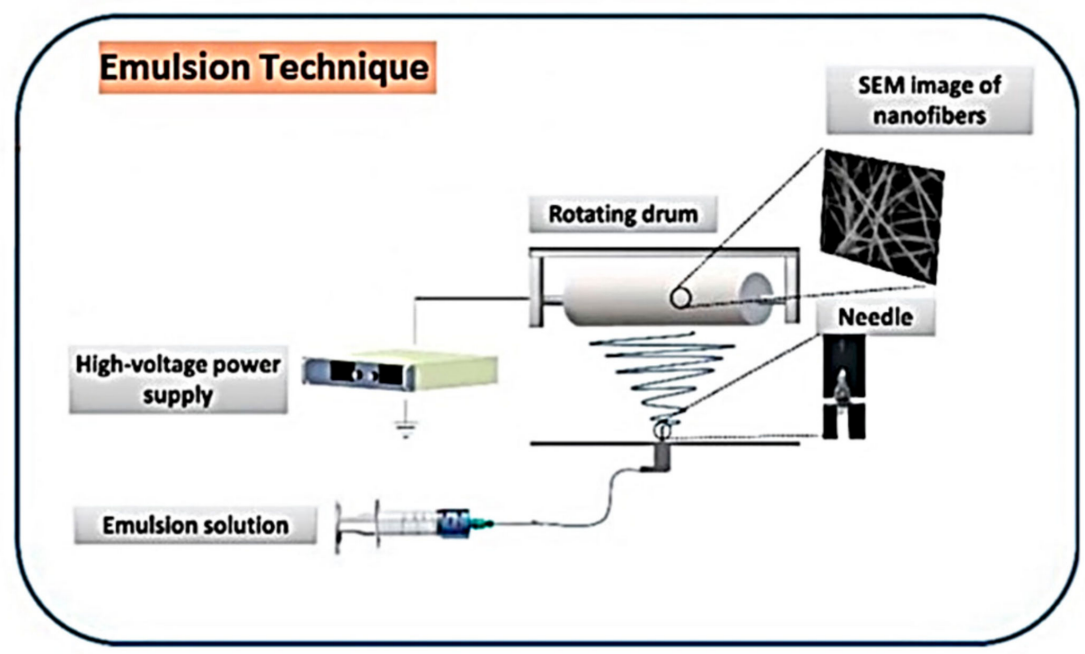

Figure 2. Schematic diagram of electrospinning: (a) Two-syringe technique, (b) Double channel nozzle technique, and (c) Single-nozzle technique; Adapted from [53], with permission from International Journal of Biological Macromolecules; Elsevier, 2021. 
Research has proven the instrumental effect of electric fields during the ES process on the degree of disorientation of the molecular chain fibers and the molecular orientation, which increases by the increase in fiber orientation [54,55]. Optimizing the ES process for PLA has been extensively deliberated in previous studies, and affecting parameters on crystallinity, orientation, uniformity, thermal stability, diameter, and strength has been partially quantified. Utilizing a rotating collector drum in the ES setup is a common procedure to obtain oriented fibers, and it has been proven that, by changing the rotation speed, the fiber orientation can be tailored.

During the ES process, the mat thickness increases; this increase weakens the potential difference between the collector and the nozzle, and thus, the fibers' alignment decreases. As the electrodes are covered with fibers, the electrostatic forces that aid the fiber orientation weaken, and it is easier to overcome the unpredictable whipping motion of the jet [56]. The process requires a very high voltage to turn a polymeric solution into thin fibers with desirable orientations. ES can be near-field or far-field depending on the type of application [57] and on the specific desired morphology.

The ES fibers can be deposited in various morphologies: aligned or randomly patterned and directly drawn to form ropes. Within this process, the fiber diameter and intermolecular dipoles causing an electrically induced strain are the points that stand to attention. Electro-spun fibers show a higher piezo constant than PLLA molded films; this is related to fibers' ultimate uniaxial alignment [58]. One of the advantages of ES is the creation of uniaxially aligned dipoles because of the presence of electrostatic forces during fiber extrusion and the pulling toward the collector plate $[59,60]$.

A study conducted by Luo et al. [61] introduces a method to select the best solvents for the ES process. Their work has proven that the best choice for ES is not necessarily related to the solvent with higher solubility, but also that balancing the electrostatic and fluidic forces should be taken into account to achieve smooth fibers. Therefore, solution conductivity, surface tension, and viscosity play essential roles.

Due to the material's dielectric constant, the mass throughput, which is exposed to the electric field, takes effect. Possibly one of the most influential parameters in the ES solution is the charge distribution. Choosing the correct solvent is another effective parameter; Dimethylformamide (DMF) is a poor solvent containing significant dipole moments and has better conductivity than chloroform. Adding small amounts of DMF can improve the electrospinning ability and decreases the solubility. When increasing the amount of DMF, beading starts to appear, attributed to a decrease in polymer chain dispersion [62].

\subsection{Electrospinning and Piezoelectricity}

The most common piezoelectric constant of PLA is defined as $d_{14}$. Through the experimental measurements of research from Occhiai et al. on 0-cut PLLA, carrying side along the $z$-axis, which was also their elongation axis, samples demonstrated that these cases had a $\mathrm{d}_{14}$ PE coefficient equal to $9.82 \mathrm{pC} / \mathrm{N}$ [2].

In an inceptive research, Zhu et al. fabricated porous electrospun $100 \mathrm{~nm}$ to $2 \mu \mathrm{m}$ nanofibres. In another research [63], they found that optimizing the ES process led to the fabrication of higher than $800 \mathrm{~nm}$ PLLA fibers. Their method included a supercritical $\mathrm{CO}_{2}$ treatment. While they used melt drawing to fabricate the samples, scaffolds containing $40 \mu \mathrm{m}$ nanofiber showed almost no piezo-response. However, aligned $100 \mathrm{~nm}$ to $40 \mu \mathrm{m}$ nanofibers revealed piezoelectricity. The importance of this study was the reporting of d33 PE constant of a single polymer fiber. An increasing linear trend for the charge while increasing the force was observed, as it has shown in Figure 3. 

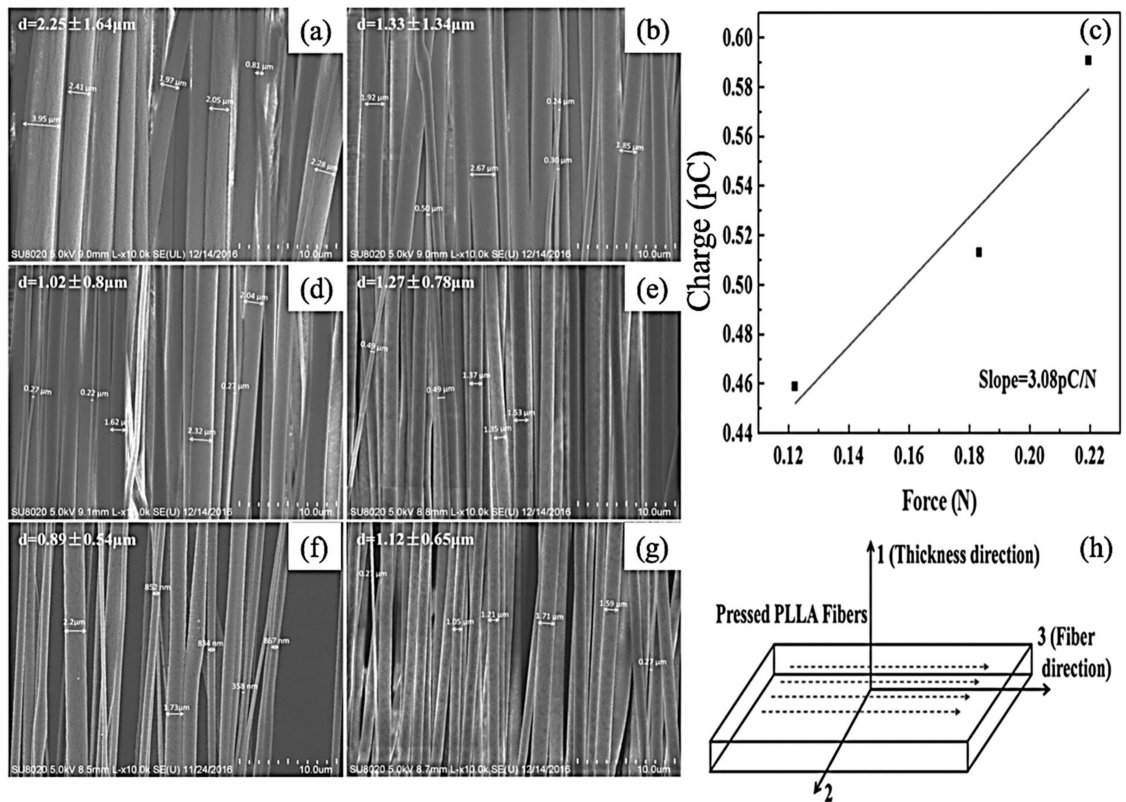

Figure 3. Scanning electron microscope (SEM) images of electrospun PLLA fibers fabricated at the distance of $10 \mathrm{~cm}$ from the needle to the rotational mandrel, a flow rate of $1 \mathrm{~mL} \mathrm{~h}^{-1}$ : (a) $1000 \mathrm{rpm}$, $9 \mathrm{kV}$; (b) $1000 \mathrm{rpm}, 12 \mathrm{kV}$; (c) $3000 \mathrm{rpm}, 15 \mathrm{kV}$; (d) $2000 \mathrm{rpm}, 9 \mathrm{kV}$; (e) $3000 \mathrm{rpm}, 9 \mathrm{kV}$; (f) $3000 \mathrm{rpm}$, $12 \mathrm{kV}$. (g) Charge versus force plot for dynamic d33 test of the electrospun PLLA fiber bundles; (h) definition of coordinates for electrospun PLLA fiber bundles; Adapted from [63], with permission from Macromolecular Materials \& Engineering; Wiley-VCH, 2015.

Lee et al. studied the effect of constructive and deconstructive PVDF and PLA electrospun fibers [64]. Constructive PLA fabricated fibers show a slightly lower piezo-response than PVDF, while in deconstructive fabricated fibers, PLA shows a higher piezo-response than PVDF. To tackle the effect of the layers' summation on the output voltage, they understood that by increasing the number of layers because of more dipole arrangement, the output voltage increases by a linear trend, and a similar result was reported for the current output. This research could use the fabricated PE to charge a capacitor to turn on an LED, as illustrated in Figure 4.

(a)

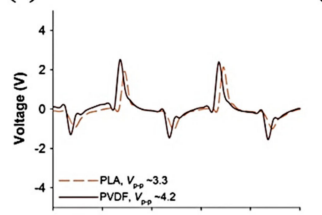

(e)

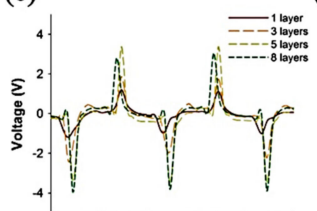

(b)

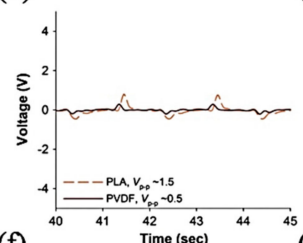

(f) (c)

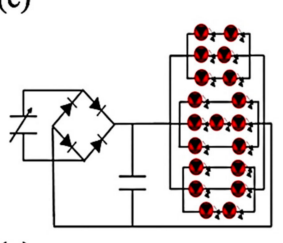

(d)

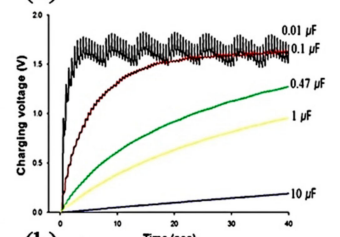

(h)
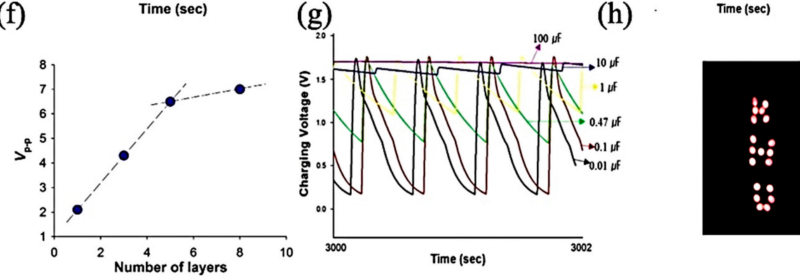

Figure 4. (a) Effect of constructive and (b) destructive stacking for PVDF and PLA nanofiber webbased sensors; (e) changes in piezoelectric output signal with increasing PLA nanoweb stacks and (f) its Vp-p comparison plot. (c) The equivalent circuit diagram to operate LED diodes; charging voltage vs. time when LEDs were (d) not connected and (g) connected for more than $3000 \mathrm{~s}$ for capacitors having different capacitances; and (h) photograph of LEDs operated using a $100 \mathrm{mF}$ capacitor; Adapted from [64], with permission from Materials Letters, Elsevier, 2015. 


\section{Poly Lactic Acid \\ 4.1. Chemistry}

PLA is produced from a natural organic acid, lactic acid, generated by the fermentation of sugars obtained from renewable supplies, such as sugarcane, and converts back to the latter when it hydrolytically degrades. Lactic acid (2-hydroxy propionic acid), $\mathrm{CH} 3-$ $\mathrm{CHOHCOOH}$, is a single chiral molecule existing as two enantiomers, L- and D-lactic acid, varying in the response of the polarized light. The optically inactive $\mathrm{D}, \mathrm{L}$, or meso form is an equimolar (racemic) mixture of $\mathrm{D}(-)$ and $\mathrm{L}(+)$ isomers [65], which is presented in Figure 5.<smiles>C[C@@H](O)C(=O)O</smiles>

L-lactic acid<smiles>C[C@@H](O)C(=O)O</smiles>

D-lactic acid<smiles>C[C@@H]1OC(=O)[C@@H](C)OC1=O</smiles>

L-lactide

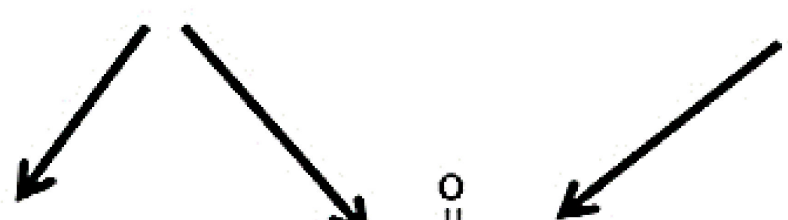

$\mathrm{CH}_{3}$

Figure 5. Polylactide acid stereo forms: L-lactide, D-lactide, and meso-lactide; Adapted from [66], with permission from Bioresource Technology; Elsevier, 2010.

The discovery of PLA goes back to 1932, when a low-molecular-weight product was constructed by Carothers (DuPont), who performed this by heating lactic acid under vacuum conditions. Then, in 1954, DuPont produced and patented PLA with a higher molecular weight. Later, in 1968, Santis and Kovacs reported on the pseudo-orthorhombic crystal structure of PLLA. The PLLA crystal structure was reported as a left-handed helix confirmation for the $\alpha$-form [67].

The PLA, which only contains L stereoisomers, is called PLLA; in contrast, when it contains only D stereoisomers, it is called PDLA. PDLLA is made of macromolecules containing both $\mathrm{L}$ and D stereoisomers (in different ratios). Both the PLLA and PDLA potentially have crystalline structures, whereas the percentage of PDLLA crystallinity depends on the $\mathrm{L} / \mathrm{D}$ ratio. The L-isomer is a biological metabolite that forms the main portion of PLA and derives from renewable sources. Most lactic acid from biological sources exists in PLLA various phases $(\alpha, \beta$, and $\gamma)$, which will be discussed in detail in the following sections [68].

Materials with 3D configurations are categorized under the stereo complexation (SC) definition; this phenomenon occurs between isostatic and syndiotactic polymers, or $\mathrm{L}$ and D configurated polymers [69]. PLLA and PDLA have unique structures among this vast polymer class because of their high-performance biodegradable plastic properties [70]. 
The crystalline structure [71], crystallization, melting behavior [72,73], and mechanical properties [74] of PLA have been studied extensively.

Formatting a 1:1 mixture of high-PLLA molecular weight with a middle molecular weight of PDLA, the best annealing condition for SC was reported by Zhang et al. [75]. The best annealing temperature was considered in the melting temperature range $\left(180{ }^{\circ} \mathrm{C}\right)$ and SC $\left(230^{\circ} \mathrm{C}\right)$. The phase transformations may occur during the heat treatment of a specified polymer, where the crystalline phase melts-and-switches to another more thermodynamically stable state through the "melting and recrystallization process." The development of SC crystals through the annealing of PLLA and PDLA single crystals was assumed by Fujita et al. to be prompted by both chain diffusion in solid-state and partial melting and recrystallization [76]. Xiong et al. discussed that the SC in the oriented PLLA/PDLA specimen takes root from the amorphous domains and molten crystals [77]. Molten $\alpha^{\prime}$ crystals crystallize to SC faster than the $\alpha$ phase because of the smaller aggregation and high SC nucleation density [78].

Poly (lactic acid) maintains a polymeric helix with an orthorhombic unit cell structure. The PLA features depend on various variables: the component isomers, processing temperature, annealing time, and molecular weight [66]. The stereochemistry and thermal history have a direct influence on PLA crystallinity and its properties. PLA containing higher than $90 \%$ PLLA content favors a crystalline structure, while the lower optically pure PLA tends to be amorphous. The melting temperature $\left(T_{m}\right)$ and the glass transition temperature $\left(\mathrm{T}_{\mathrm{g}}\right)$ of PLA are functions of numerous variables such as the L/D ratio, the PDLA macromolecules, crystallinity, chain alignment, confinement, etc. [79].

PLLA has attained glorious considerations because of its unique biocompatibility $[80,81]$ and mechanical properties. However, its long degradation times, coupled with its high crystallinity, can cause erythrogenic reactions. Overcoming this drawback, PLA can be used as a material combination of L-lactic and D, L-lactic acid monomers. The latter is rapidly degraded without forming crystalline fragments during this process [82-85].

Generally, crystalline/amorphous polymer films consist of an aggregation of large molecular chains [86], with covalently bonded units [87-89]. PLLA has a complex higherorder structure of mixed crystalline and amorphous regions [90,91]. For example, in macromolecular materials, obtaining a 100\% crystalline structure in macromolecular materials with conventional methods is impossible, and a proportion of an amorphous region is necessary because of the complexity of the structure [92].

\subsection{Structural Evolution}

\subsubsection{Crystalline-Amorphous Combination}

Many semicrystalline polymers tend to have many polymorphic phases, and mechanical processes, thermal annealing, and high voltage treatment cause crystalline phase transformation by which various properties result. The degree of crystallinity/amorphous structure is defined as long/short-range ordering in the structure. It has been demonstrated that different properties such as the PE constant of PLLA are a function of the degree of its crystallinity and, of course, its molecular orientation [93,94]. Aligned electrical dipoles in the carbon-oxygen double bonds $(\mathrm{C}=\mathrm{O})$, which are branched out of the polymer backbone, are the main reason for $\mathrm{PE}[63,95]$.

Because of the formation of an amorphous sample based on the solvent's inherent evaporation process, the pieces achieved by this would show a cold crystallization peak from themselves under DSC analysis. This fast solvent evaporation is an obstacle to crystalline phase formation. Choosing the correct temperature to form any further crystalline phases ought to bring attention to this $\mathrm{T}_{\mathrm{cc}}$. The degree of stretching during hot drawing is related to the uniformity of fiber density and their alignment; another effective parameter is sweeping along the acrylic side [27]. Ribeiro et al. described these phenomena as frozen nucleation sites or non-equilibrium chain conformations and mentioned that spontaneous crystallization through the annealing process would be achieved [96]. 
Agrawal et al. [97] found a potential to increase crystallinity by the annealing process. A simultaneous combination of annealing and drawing allows a high proportion of polymer chains to crystallize under stress-controlled orientation [27]. The research explains that $\mathrm{C}=\mathrm{O}$ polarization bonds might be canceled out along the amorphous PLA chain, resulting in no piezoelectric constant [98]. ES produces a metastable crystalline state and can orient the fibers [99], achieving a crystalline phase that needs post-processing.

The degree of crystallinity in PLA can vary between 0 and $50 \%$ by optimizing several factors, for instance, temperature, processing parameters, and solvents [96]. In research that has been conducted by Zong et al. [99], they found that PLLA fibers which were electrospun show much less crystallinity than the as-received PLLA but that cold crystallization occurred more efficiently due to molecular orientation. Thanh D. Nguyen et al. reported an annealing fabrication process to PLLA nanofibers to enhance the degree of crystallinity up to $80 \%$. This work advanced the PE $\mathrm{d}_{14}$ constant of PLLA up to nearly $19 \mathrm{pC} / \mathrm{N}$ [98].

\subsubsection{Crystalline Phase Study; FTIR-XRD}

One of the simplest PE PLA fabrication methods is based on the molding. Drawn PE PLLA films must conclude with chiral molecules forming a spiral in an arrangement along a single direction of the orthorhombic crystal. A molding procedure is not easy to align PLLA chain molecules along one axial direction [100,101]. As a result, the fabricated samples cannot exhibit PE from themselves or the most modest possible PE because of the polarity cancellation in the structure.

Considering the polymers, an individual polymer chain may be non-centrosymmetric. While stationing the amorphous network, these polymer chains will be in a highly graded isotropic state possessing a center of symmetry, which should be removed for the appearance of PE. This issue is solved chiefly by crystallization; among the 32 crystallographic point groups, 21 do not possess inversion symmetry, which is favorable for polymers to crystalline into one or two of them. In this way, multiple crystalline regions will nucleate and grow within the amorphous matrix and exhibit a random orientation distribution and show any level of preferential crystalline planes (texture) presence [102].

As a semicrystalline polymer, the crystallization process and crystal structure of PLA have been studied by various groups. PLA has the potential to form four kinds of crystal modifications, namely, $\alpha, \alpha^{\prime}, \beta$, and $\gamma$ [103-107], as a function of the preparation process. The most thermodynamically stable phase, the $\alpha$ form, has a $10_{3}$ helical chain conformation [108], which can crystallize from melt or solution and mainly differentiates from the $\alpha^{\prime}$ form. Based on the disorder to order phase transformation, the $\alpha^{\prime}$ form has been known to be the disorder form of $\alpha$. The $\alpha^{\prime}$ form crystallizes at temperatures below $120{ }^{\circ} \mathrm{C}$, while the $\alpha$ form achieves above that [105]. Table 1 epitomizes PLA crystalline phases' information.

Table 1. PLA crystalline phase information.

\begin{tabular}{|c|c|c|c|c|}
\hline Crystalline Phase & Unit Cell & Conformation & Formation Condition & References \\
\hline$\alpha$ & $\begin{array}{c}\text { Orthorhombic } \\
\mathrm{a}=9.95 \AA, \mathrm{b}=6.25 \AA, \mathrm{c}=8.8 \AA\end{array}$ & $10_{3}$ left-handed helix & Crystalizes above $120^{\circ} \mathrm{C}$ & [104] \\
\hline$\alpha^{\prime}$ & $\begin{array}{c}\text { Pseudo-hexagonal } \\
\mathrm{a}=\mathrm{b}=6.2 \AA, \mathrm{c}=28.8 \AA\end{array}$ & $10_{3}$ distorted helix & Crystalizes below $120^{\circ} \mathrm{C}$ & [105] \\
\hline$\beta$ & $\mathrm{a}=\mathrm{b}=10.52 \AA \AA \mathrm{c}=8.8 \AA$ & $\begin{array}{l}3_{1} \text { left-handed helix with } \\
\text { frustrated structure }\end{array}$ & $\begin{array}{l}\text { Drawing ratio } \geq 6 \\
\quad \mathrm{~T} \approx \mathrm{T}_{\text {melting }}\end{array}$ & [106] \\
\hline$\gamma$ & $\begin{array}{c}\text { Orthorhombic } \\
\mathrm{a}=9.95 \AA ⿱ \AA\end{array}$ & $\begin{array}{l}3_{1} \text { antiparallel left-handed } \\
\text { helix }\end{array}$ & $\begin{array}{c}\text { Epitaxial crystallization } \\
\text { on hexamethylbenzene } \\
\text { (HBM) substrate }\end{array}$ & [107] \\
\hline
\end{tabular}

Cocca et al.'s fabrication technique was composed of compression-molded and quenched samples followed by an annealing process; they contended that by increasing the annealing temperature, the reflections of $(110) /(200)$ and (203) planes shift to higher angles together with 
an increase in the intensity of the (010) and (015) planes. Furthermore, at the diffraction peaks at $2 \theta=12.5,20.8,23,24.1$, and 25.1, they would appear at higher crystallization temperatures which are assignable to the reflections of the (004)/(103), (204), (115), (016), and (206) planes of $\alpha$ polymorphism, respectively. In comparison, they will not appear at temperatures lower than $95^{\circ} \mathrm{C}$. The formation of $\alpha^{\prime}$ could be attributed to this temperature. The $\alpha$ and $\alpha^{\prime}$ polymorphism is highly related to their molecular weight; in the reported paper, the construction of $\alpha$ is devoted to temperatures higher than $145^{\circ} \mathrm{C}$, and in the range of $105-125^{\circ} \mathrm{C}$, both $\alpha$ and $\alpha^{\prime}$ are able to be achieved at the $95{ }^{\circ} \mathrm{C}$ that is associated with $\alpha^{\prime}$. As shown in Figure 6, the research article also studies the correlation between the crystalline phases and the mechanical properties. The relation of Young's modulus and crystal fraction increases but not in a linear trend for semicrystalline materials, resulting from the mobile amorphous fraction, which implies applied stress transformation across the amorphous-crystalline interface and can affect the response of semicrystalline structure [103].

(a)

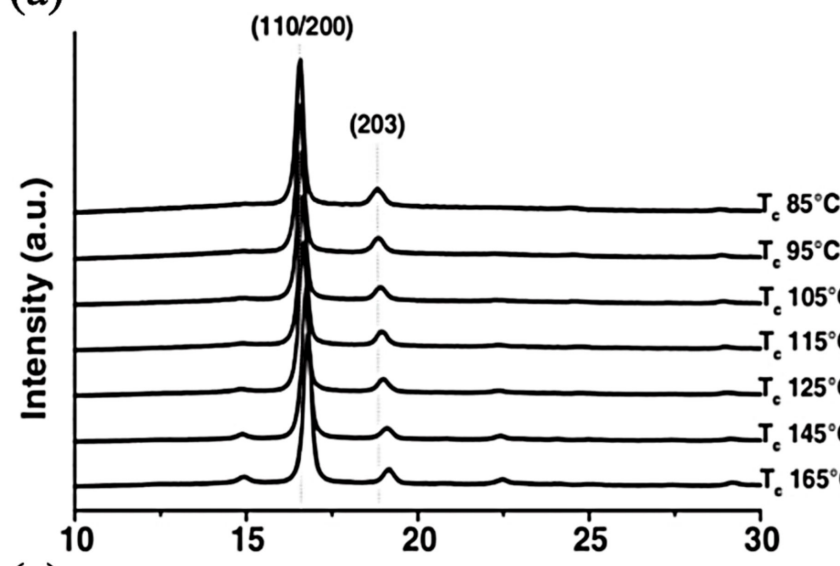

(c)

(b)

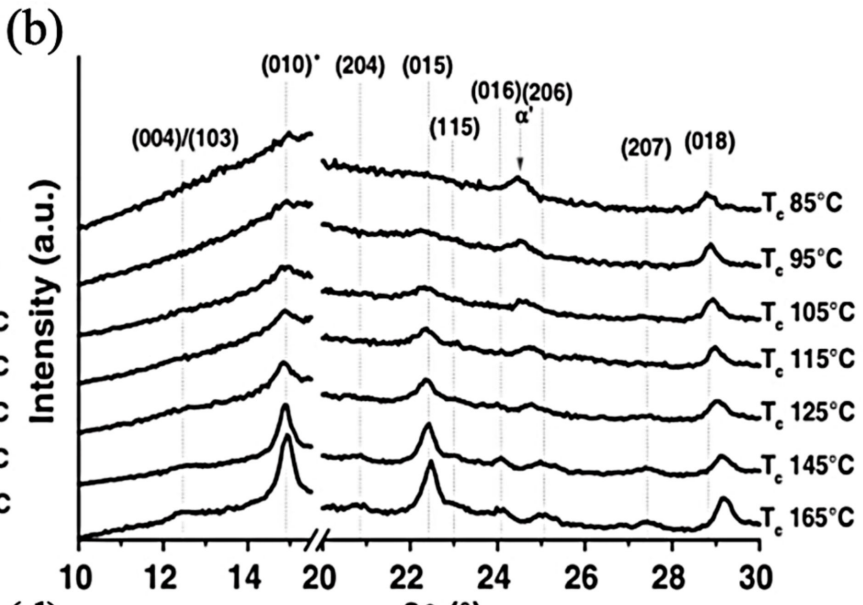

(d)

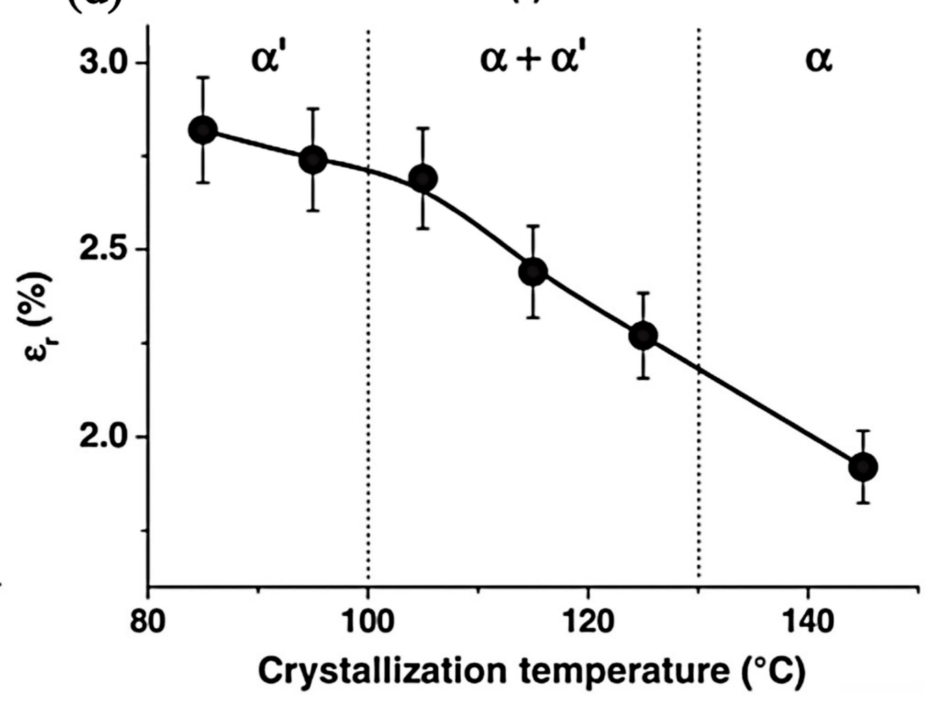

Figure 6. (a) XRD profiles of PLLA samples crystallized at different Tc; (b) Enlarged WAXD profile of PLLA samples crystallized at different Tc; (c) Young's modulus of PLLA films as a function of the degree of crystallinity; (d) Elongation at break of PLLA films as a function of Tc; Adapted from [103], with permission from European Polymer Journal; Elsevier, 2011.

Calculating the crystallite size (L) is available by Scherrer's equation as it has been checked in the following parts; where $\beta_{1 / 2}$ is the width of the peak at half intensity, $\lambda$ is the 
wavelength of $\mathrm{Cu}-\mathrm{K}_{\alpha}$ radiation $\left(1.5418 \mathrm{~A}^{\circ}\right)$, which is primarily used in $\mathrm{XRD}$ characterization, and $\mathrm{K}$ is the broadening constant as 0.9 for imperfect polycrystal [106].

$$
\mathrm{L}=\frac{\mathrm{K} \times \lambda}{\beta_{\frac{1}{2}} \cos \theta}
$$

The $\beta$ form is obtained under a severe, high-temperature-drawing condition with lefthanded frustrated $3_{1}$ helical conformations and encompassed of the trigonal unit cell with $\mathrm{a}=\mathrm{b}=1.052 \mathrm{~nm}, \mathrm{c}=0.88 \mathrm{~nm}[109,110]$, capable of accommodating the random up-down oriented neighboring chains [111,112], and finally, the $\gamma$ can be achieved by an epitaxial crystallization route on the hexamethyl benzene substrate [113].

As mentioned previously, PLA is also polymorphic, with its corresponding $\alpha$ and $\alpha^{\prime}$ phases being the most common. The $\beta$-phase is found in drawn PLA samples in the same type of samples which are frequently used for PE analysis. This has made some researchers believe that the $\beta$-phase is necessary for the PE property [63]. While it is not correct, in this course, both the $\beta$-phase and PE are a consequence of drawing, and in this way, the presence of the $\beta$-phase is not a requirement for PE. PE is observed in samples drawn to a ratio of two [114], whereas significant proportions of the $\beta$-phase are not formed until draw ratios of at least four are achieved [115].

In the case of PLA identification, the orientation of PE crystallites must be performed by X-ray diffraction (XRD) [100]; however, because of the disturbance and low degree of crystallinity, it is hard to obtain a sharp pattern [116]. Therefore, controlling the structure of the PLA distributed in the amorphous region is important, while exhibiting macro-PE is expected. Smith et al. discuss the importance of the crystalline structure in polymers; they have proven the importance of a non-centrosymmetric structure on the appearance of the PE property.

Both of the $\alpha$ and $\alpha^{\prime}$ phases show (110)/(200) and (203) crystalline planes considering the $\mathrm{XRD}$ results while at $2 \theta=16.8^{\circ}$ and $19.1^{\circ}$ and $2 \theta=16.4^{\circ}$ and $18.9^{\circ}$ for $\alpha$ and $\alpha^{\prime}$, respectively. Low-intensity peaks at $2 \theta=14.9^{\circ}$ and $22.4^{\circ}$ have been assigned for (010) and (211) $\alpha$ phase reflection, whereas such a weak reflection peak can just be found at $2 \theta=24.6^{\circ}$ for the (206) crystalline plane of $\alpha^{\prime}$ [112]. Cury et al. [117] had investigated the effect of the drawing ratio on PE properties of PLLA. The investigation on PLLA film showed that there are three crystalline phases which can be attributed to the (111), (200), and (110) crystalline planes. The intensity of (111) slumped by increasing the drawing ratio results from phase transformation from $\alpha$, incorporating a left-handed $10_{3}$ helical conformation to $\beta$, with a $3_{1}$ helical conformation. As depicted in Figure 7 , The optimum drawing ratio, which has the potential to maximize the PLLA film crystallinity, was five, and further elongations decrease the degree of crystallinity. This research used shear stress to monitor the generated electric potentials in drawn films. Because of crystalline phase transformation, films with drawing ratios between 2.5 and 4.5 showed the best PE response. Not considering the degree of crystallinity, uniaxial deformation has a promising potential to align the polar $\mathrm{C}=\mathrm{O}$ polymer chain bonds and enhance $\mathrm{PE}$. 
(a)

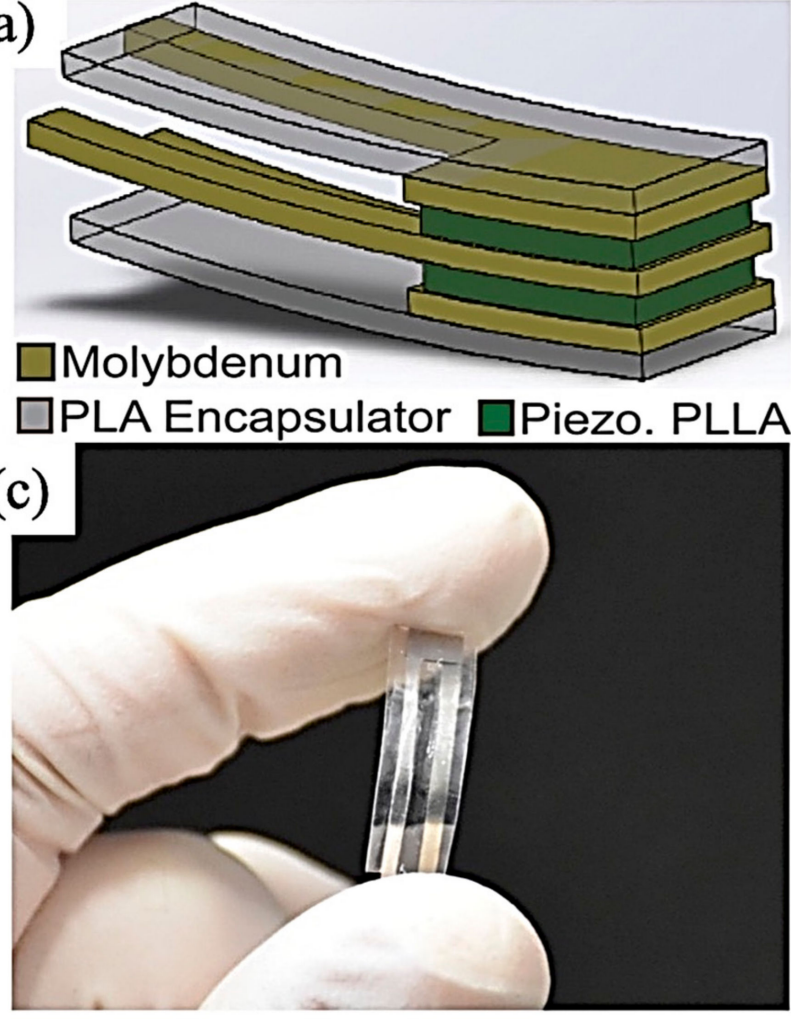

(e) 0.8

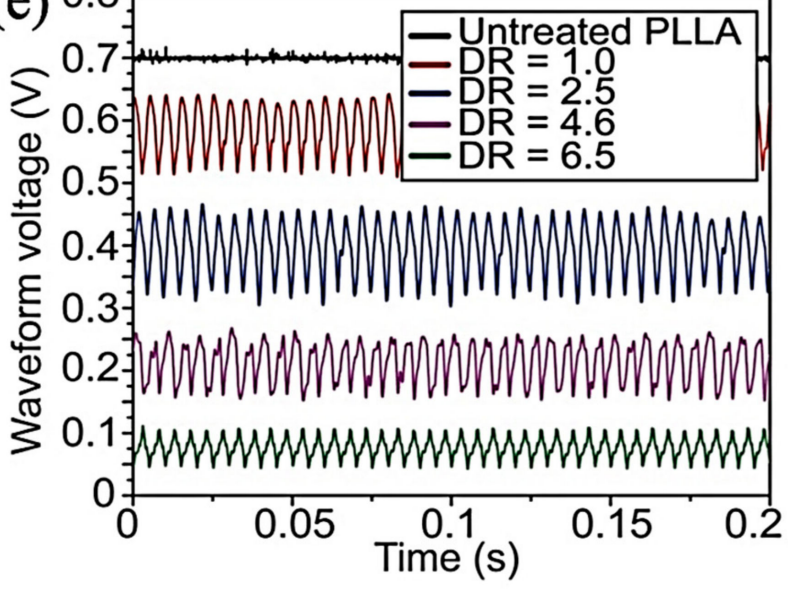

(b)

(200) \& (110)

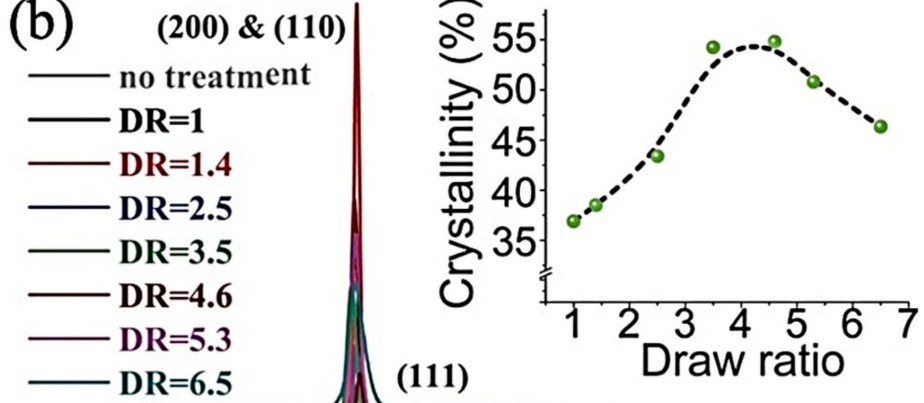

(111)

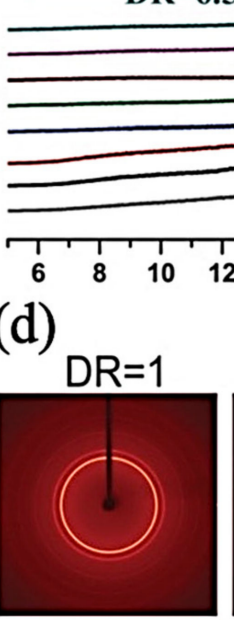

(f)

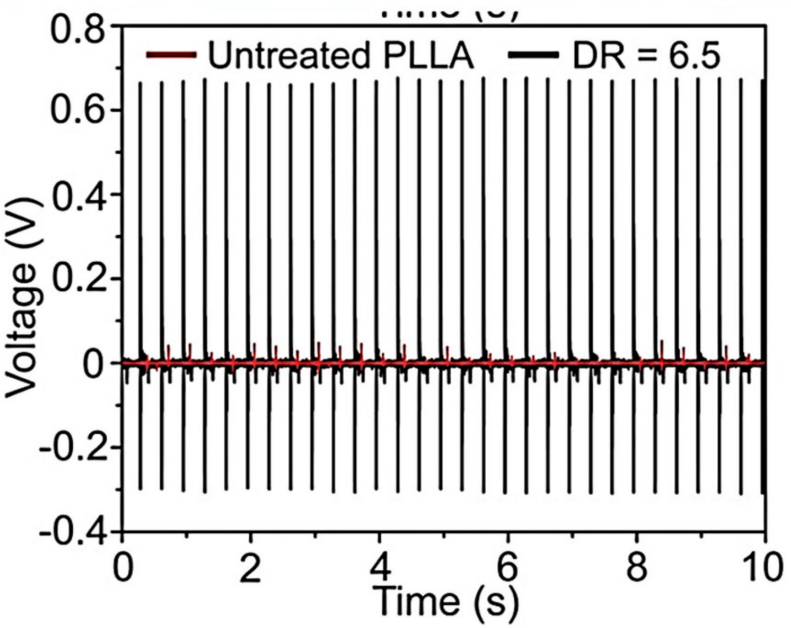

Figure 7. Biodegradable piezoelectric PLLA pressure sensor: (a) Simplified schematic representing the biodegradable piezoelectric PLLA sensor; (c) Optical image of a fabricated biodegradable piezoelectric PLLA sensor $(5 \mathrm{~mm} \times 5 \mathrm{~mm}$ and $200 \mu \mathrm{m}$ thick). Characterization of crystallinity and polymer chain orientation for processed PLLA: (b) Results from one-dimensional (1D) XRD of stretched PLLA films with different DRs. (Inset) Crystallinity percentage of the processed PLLA for different DRs, quantified from the 1D XRD spectrum. (d) Two-dimensional XRD images show the polymer chain's orientation of the stretched PLLA films with other DRs. Characterization of piezoelectric PLLA output from vibration and impact modes: (e) Voltage output from the treated PLLA with different DRs under a vibration at $200 \mathrm{~Hz}$. (f) The voltage output from an untreated PLLA (red) and treated PLLA (black, DR =6); Adapted from [117], with permission from Proceedings of the National Academy of Sciences of the United States of America, 2018.

Considering the crystallization from an amorphous state, FTIR characterization ought to have good potential to study the phase transformations; in this way, small bands at $921 \mathrm{~cm}^{-1}$ and $955 \mathrm{~cm}^{-1}$ wavenumbers are assigned to amorphous and $\alpha$ crystalline modes with $10_{3}$ helices, respectively, and the absence of $908 \mathrm{~cm}^{-1}$ peaks indicates the presence 
of the $\beta$ form [113]. One of the essential PLA bindings is the $\mathrm{C}=\mathrm{O}$, which can be found around $1745 \mathrm{~cm}^{-1}$ for $\alpha$ and $1755 \mathrm{~cm}^{-1}$ for $\alpha^{\prime}$ [118].

PLA melt extrusion and subsequent warm stretching at 65,90 , and $120^{\circ} \mathrm{C}$ at a constant drawing ratio of $5.4 \mathrm{~m} / \mathrm{min}$ was utilized to study the $\alpha$ and $\alpha^{\prime}$ phases. Mi et al.'s research suggested that it is hard to identify two phases by 1D-XRD due to their similarity in diffracted peaks, but FTIR results are reliable in this course. The carbonyl stretching vibration bands showed a complex splitting pattern at 1776, 1759, and $1749 \mathrm{~cm}^{-1}$. In the $\alpha^{\prime}$ phase PLA film, the carbonyl stretching vibration bands had only a single peak at $1759 \mathrm{~cm}^{-1}$ [119]; it should be noted that the peak positions shift due to the processing method. Table 2 illustrates a vital conformation study on PLA C $=\mathrm{O}$ branched out bond.

Table 2. FTIR $\mathrm{C}=\mathrm{O}$ absorption wavenumbers corresponding to their conformation state, produced from the data available in [120], Marcromulecules, ACS, 2009.

\begin{tabular}{ccccc}
\hline Conformation & g-g & t-g & g-t & t-t \\
\hline Wavenumber $\left(\mathbf{c m}^{-1}\right)$ & 1777 & 1767 & 1758 & 1749 \\
$\delta$ (Phase) & $0^{\circ}$ & $72^{\circ}$ & $108^{\circ}$ & $180^{\circ}$ \\
Helix type & - & $5_{1}$ & $10_{3}$ & $2_{1}$ \\
\hline
\end{tabular}

Considering the IR spectroscopy technique, all of the PLLA samples show a band at $921 \mathrm{~cm}^{-1}$, which assigns to $\mathrm{C}-\mathrm{C}$ backbone stretching with the $\mathrm{CH} 3$ rocking mode and is sensitive to the $10_{3}$ helix chain conformation of PLLA $\alpha$ crystals while the peak at $908 \mathrm{~cm}^{-1}$ is a denoted wavenumber for $\beta$ polymorphism formation. The $\mathrm{C}=\mathrm{O}$ stretching band appearing in the ranges of $1810-1710 \mathrm{~cm}^{-1}$ and $1500-1300 \mathrm{~cm}^{-1}$ is associated to $\mathrm{CH} 3$. Annealing above $100{ }^{\circ} \mathrm{C}$ can induce a new band appearance: (1) at $1749 \mathrm{~cm}^{-1}$, which is related to the $\mathrm{C}=\mathrm{O}$ bond; (2) the band splitting of the $\mathrm{CH} 3$ asymmetric deformation mode around $1458 \mathrm{~cm}^{-1}$ and the $\mathrm{CH} 3$ symmetric deformation mode around $1386 \mathrm{~cm}^{-1}$; and (3) in the second-derivative spectra, two new high-frequency bands (3006 and $2964 \mathrm{~cm}^{-1}$ ) around the vas $(\mathrm{CH} 3)$ and $v \mathrm{~s}(\mathrm{CH} 3)$, respectively, become much clearer with the increasing crystallization temperature over $100{ }^{\circ} \mathrm{C}$. As it is obvious in Figure 8 , all in all, there are signs of $\alpha$ crystalline phase formation [121].

The physical crosslinking of macromolecular semi-crystalline PLA induces tensile drawing, and other thermo-mechanical processes will restrict PLA chains' motion. Controlling polymer chain regulation affects the polymer microstructural evolution through stretching and annealing as a post-process [122]. The structural development through these types of designed procedures would make it possible to achieve various crystalline phases with different mechanical properties; for instance, $\gamma$ isotropic crystallites toughened the sample by highly stretching the films concerning a high applied drawing ratio [123]. 


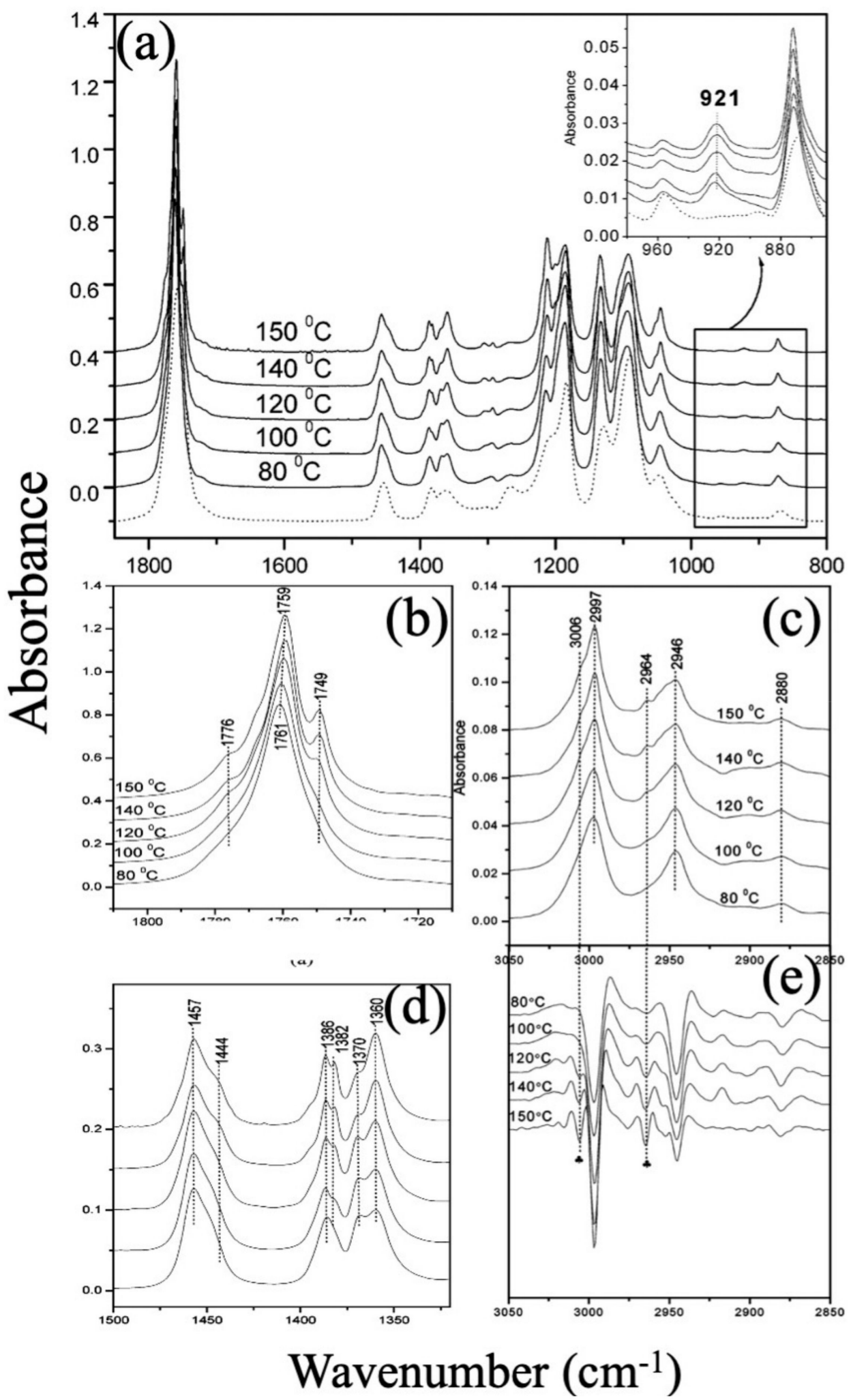

Figure 8. (a) IR spectra in the range $1850-800 \mathrm{~cm}^{-1}$ of various PLLA samples prepared by annealing at different temperatures from the amorphous state as indicated on the lines for $1 \mathrm{~h} ;(\mathbf{b}, \mathbf{d})$ Enlarged IR spectra of PLLA samples prepared by annealing at $80,100,120,140$, and $150{ }^{\circ} \mathrm{C}$ (b) $1810-1710 \mathrm{~cm}^{-1}$, (d) 1500-1320 $\mathrm{cm}^{-1}$; (c,e) IR spectra and the second derivatives in the $3050-2850 \mathrm{~cm}^{-1}$ region of PLLA samples prepared by annealing at 80, 100, 120, 140, and $150{ }^{\circ} \mathrm{C}$; Adapted from [121], with permission from Macromolecules; American Chemical Society Publications, 2005. 


\subsubsection{Texturization Study}

As Chirachanchai et al. [124] (Figure 9) observed, PLA shows a completely cloudy 2D XRD trend. While the addition of thermoplastic starch (TPS) has the potential to form PLA crystalline phase, a spot pattern, as a matter of TPS, has a nucleation role for PLA in addition to the rate and type of drawing ratio. Moreover,2D-WAXS is a pluripotent characterization technique to investigate the molecular orientation of the samples. It has been understood that the polymeric chains' alignment is the function of thermo-mechanical processing. Both the strain and temperature are the functions that should be considered in this course. In research, it was indicated that the orientation inclination of the molecular chain occurred along drawing direction. It is demonstrated that at $65^{\circ} \mathrm{C}$ and $90{ }^{\circ} \mathrm{C}$, strong fiber texture developed progressively at drawing ratios above DR3. Herman's orientation function investigates the degree of molecular alignment by the following equation [119]:

$$
\mathrm{f}_{\mathrm{c}}=\frac{3\left(\cos ^{2} \alpha-1\right)}{2}
$$
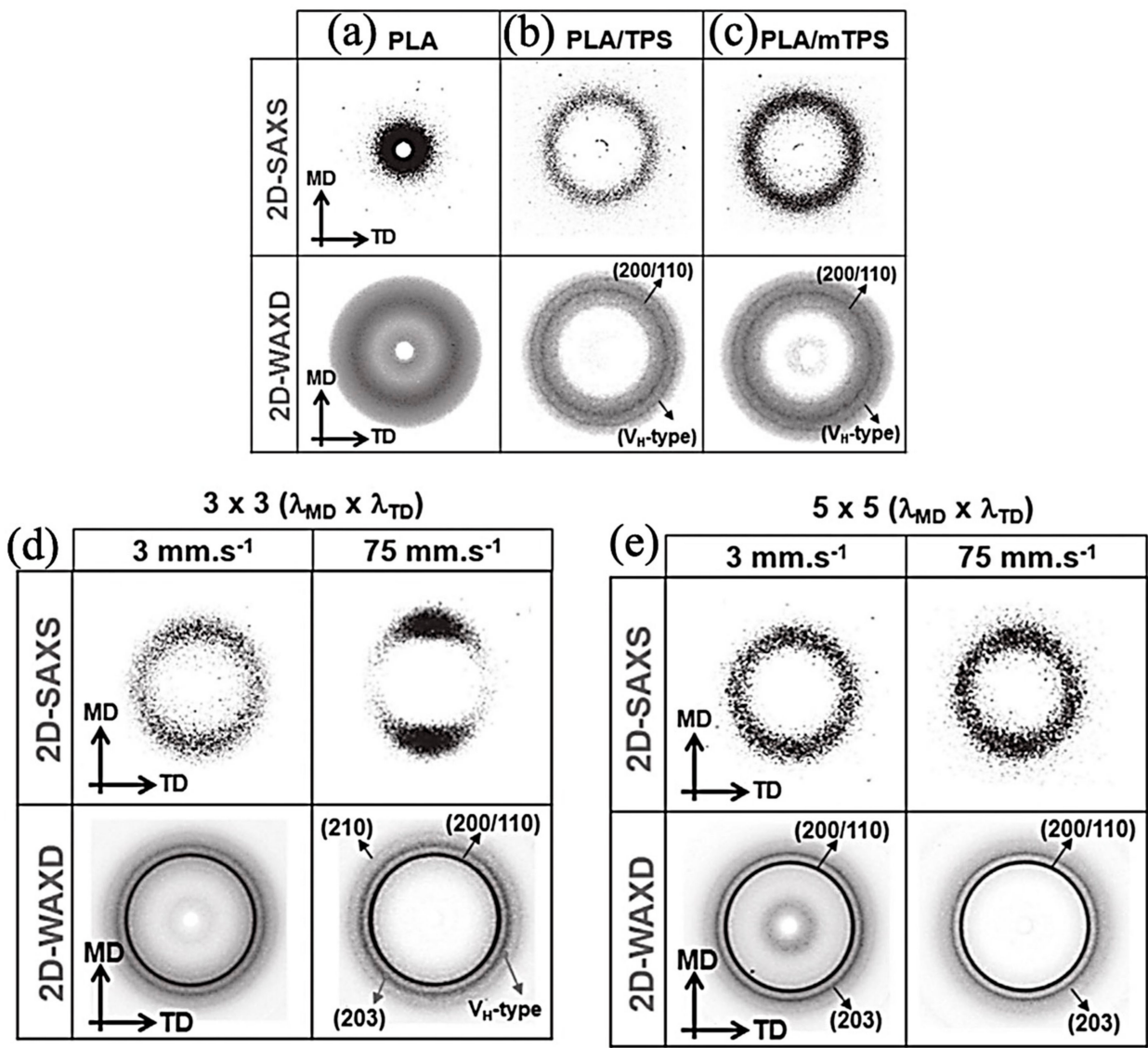

Figure 9. The 2D-SAXS and 2D-WAXD patterns of (a) PLA, (b) PLA/TPS, and (c) PLA/mTPS precursor sheets, respectively. (d,e) The 2D-SAXS and 2D-WAXD patterns of BO-PLA/TPS with varied stretching rates and draw ratios $(3 \times 3$ and $5 \times 5)$; Adapted from [124], with permission from Macromolecular Materials and Engineering; Wiley-VCH, 2019.

$\mathrm{F}_{\mathrm{C}}$ is the orientation index and would be equal to 0 where there are randomly oriented chains and 1 where the chains are perfectly oriented, and $\cos ^{2} \alpha$ is the average cosine value associated between the polymer chain axis and the drawing direction. The latter paper shows the value of $f_{c}$ increased with increasing the drawing ratio and causing the chain alignment along the uniaxial draw direction due to strain-induced crystallization.

In order to understand the PLLA crystalline structure phase transformation, mold casting at numerous temperatures and various drawing ratios was considered [115]. The best results to analyze were achieved when the temperature intervened between $T_{m}$ and $T_{g}$ 
at $170{ }^{\circ} \mathrm{C}$. While the extrusion drawing ratio (EDR) was 1,3 , the $\alpha$ phase was achieved with any texturizing crystalline planes, while at higher drawing ratios of 3,9 , the $\beta$ crystalline phase started to appear and texturization happened. The research denotes that the (200) of $\beta$ phase crystalline plane coincides with appearing with $(200) /(100) \alpha$ at the lower drawing ratios, although at $E D R=11$, the complete $\beta$ crystalline phase is achieved with the absence of $\alpha$. The results of this study are presented in Figure 10.

\section{Temperature: $170^{\circ} \mathrm{C}$}
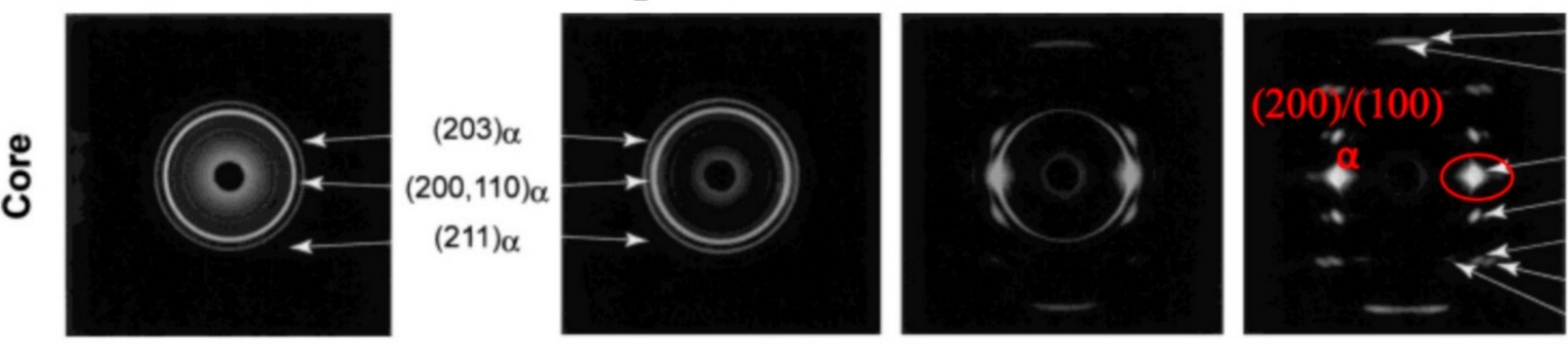

$(023) \beta$ $(003) \beta$

Absence of $\beta$ crystalline
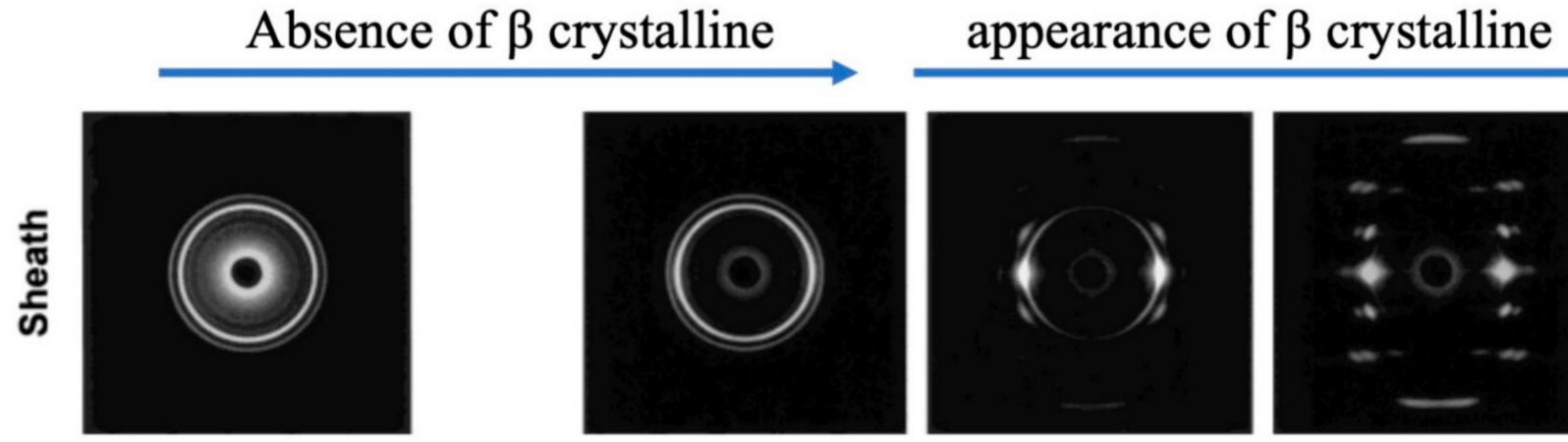

$E D R=1$

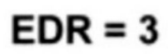

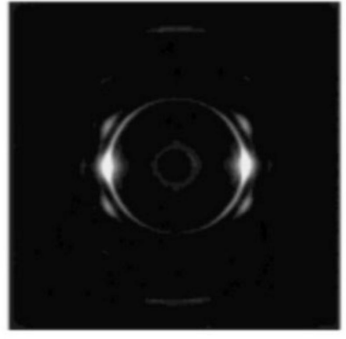

$E D R=6$

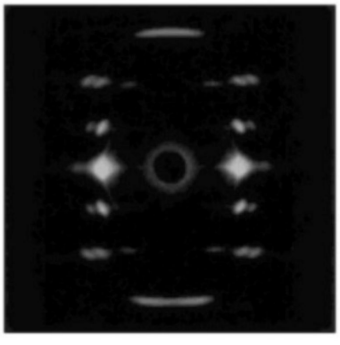

$E D R=9$

Figure 10. $\alpha$ to $\beta$ crystalline phase transformation induced by different drawing ratios; Reproduced from [115], with permission from Macromolecules; ACS Publications, 2003.

\subsection{PLA Piezo-Polymer}

Since the first discovery of the PE biopolymers in 1941 [106], PLA has emerged as the most attractive nominee to replace current PE materials. PLA offers more outstanding processability and a more comprehensive range of applications compared to PE-ceramics because of its flexibility and lightweight. It should be taken into account that the PLA PE strain-constant is remarkably low, and improving the PLA PE constant is the driving force of many researchers to make it a considerable alternative for conventional PEs [13,101]. PLA has unique piezo properties comparable with PVDF and other piezo-ceramics, affiliated with the chiral center of lactic acid [104,107].

In another point of view, PLA has not been classified under ferroelectric materials, and uniaxial alignment would act enough to implicate its inherent piezo-response. Accordingly, because of the inherent PE properties of the PLA, no other fabrication process other than stretching treatment, which is necessary to induce uniaxially oriented chains, is required. Inducing the PE is also possible by thermally stretching the polymer; by this process, the phase transition from $\alpha$ to $\beta$ happens, so a change from randomly oriented molecular chains to aligned chains might be achieved [125].

A typical PLA thermoplastic biopolymer maintaining chirality and its Levo derivative, poly-l-lactide (PLLA) with 37\% crystallinity, is reported for its high PE behavior $\left(\mathrm{d}_{14}=-10 \mathrm{pC} / \mathrm{N}\right)$ [25]. Another study reports the $\mathrm{d}_{14}$ value of PLLA as $7-12 \mathrm{pC} / \mathrm{N}$ and the $\mathrm{d}_{33}$ value as $0.21 \mathrm{fC} / \mathrm{N}$ for fabricated scaffolds [126]. (smaller than PZT) and dielectric constant 2.5, making large PE output constant roughly similar to that of PVDF (both $\mathrm{d}_{33}$ 
and dielectric constants are high in this case). This advantage of shear PE of PLA is applied in developing sensors as well [26]. Table 3 provides an appropriate comparison between various piezoelectric materials mentioned in the literature.

Table 3. A comparison of different piezoelectric constant of materials; Reproduced from [127], with permission from Advanced Materials; Wiley-VCH, 2018.

\begin{tabular}{ccc}
\hline Piezoelectric Material & Material Type & Piezoelectric Constant \\
\hline PZT-5H & Anisotropic (Orthorhombic), Ceramic & $\mathrm{d}_{33}=593(\mathrm{pC} / \mathrm{N}), \mathrm{d}_{31}=-274(\mathrm{pC} / \mathrm{N})$ \\
AIN & Anisotropic, Ceramic & $\mathrm{d}_{33}=3-6(\mathrm{pC} / \mathrm{N}), \mathrm{d}_{31}=-2(\mathrm{pC} / \mathrm{N})$ \\
Quartz & Anisotropic (Orthorhomic), Single crystal & $\mathrm{d}_{11}=2.3(\mathrm{pC} / \mathrm{N}), \mathrm{d}_{14}=-0.67(\mathrm{pC} / \mathrm{N})$ \\
ZnO & Anisotropic, Crystal & $\mathrm{d}_{33}=6-13(\mathrm{pC} / \mathrm{N}), \mathrm{d}_{31}=-5(\mathrm{pC} / \mathrm{N})$ \\
BaTiO $_{3}$ & Anisotropic (Orthorhombic), Ceramic & $\mathrm{d}_{33}=190(\mathrm{pC} / \mathrm{N}), \mathrm{d}_{31}=-78(\mathrm{pC} / \mathrm{N})$, \\
LiNbO $_{3}$ & Anisotropic (Orthorhombic), Ceramic & $\mathrm{d}_{33}=16(\mathrm{pC} / \mathrm{N}), \mathrm{d}_{31}=-1(\mathrm{pC} / \mathrm{N})$ \\
PMN-PT & Anisotropic, Single Crystal & $\mathrm{d}_{33}=2000-3000(\mathrm{pC} / \mathrm{N})$ \\
GaN & Anisotropic, Crystal & $\mathrm{d}_{33}=2-4(\mathrm{pC} / \mathrm{N}), \mathrm{d}_{31}=-1.5(\mathrm{pC} / \mathrm{N})$ \\
PVDF & Anisotropic, Polymer & $\mathrm{d}_{33}=-33(\mathrm{pC} / \mathrm{N}), \mathrm{d}_{31}=23(\mathrm{pC} / \mathrm{N})$, \\
PLLA & Anisotropic (Transversely Isotropic), & $\mathrm{d}_{14}=6-12(\mathrm{pC} / \mathrm{N}), \mathrm{d}_{33}=3.08(\mathrm{pC} / \mathrm{N})$ \\
$\beta$-Glycine & Polymer & $\mathrm{d}_{16}=196(\mathrm{pm} / \mathrm{V})$ \\
Collagen & Anisotropic, $\beta-C r y s t a l$ & $\mathrm{~d}_{14}=0.1(\mathrm{pm} / \mathrm{V})$ \\
Silk & Anisotropic, Non-oriented & $\mathrm{d}_{16}=-1.5(\mathrm{pC} / \mathrm{N})$ \\
Peptide Nanotubes & Ratio = 2.7 & $\mathrm{d}_{15}=60(\mathrm{pm} / \mathrm{V})$ \\
Graphene & Anisotropic, Semi-Crystalline, Drawing & $\mathrm{d}_{33}=1.4(\mathrm{~nm} / \mathrm{N})$ \\
\hline
\end{tabular}

On the other hand, the existence of the lead, which leaches from the best performed PZT family PE, restricts its application potential [128]. The alternative group for PZTs is lead-free piezo-ceramics such as Barium Titanate Oxide (BTO) and potassium sodium Niobate (KNN)-based materials. The barrier of this group is the limitation of recycling and the non-environmentally friendly destruction products, along with the lack of flexibility [129].

In helical PLA molecule chains, shear strain in the direction of the helix axis slightly rotates the permanent bond dipoles and thus alters the polarization perpendicular to the plane of shear strain $[114,130]$. One of the drawbacks in this field is the PLA magnitude of PE, which is much lower than most other piezo-electrics. To overcome this drawback, scientists, on the one hand, started to fabricate hybrid biomaterials and, on the other hand, focused on phase transitions and stabilizing them. The convention magnitude between mechanical applied deformation and the electricity generated charge is a function of the PE constant [131].

Micro/nanoscale PE observations are possible by advanced characterization techniques [91,132]. For instance, Smith et al. reported the measurement of shear PE in highly oriented PLLA nanowires which were also highly crystalline; the analyzed result concluded an increase in the degree of crystallinity up to 70\%, using PE Force Microscopy (PFM) [91]. In his study, nanowires were grown on a confined aluminum oxide template. They detected a sharp vertical response at the edge of the nanowires, denoting great shear PE. On the other hand, a significant deflection was detected in the lateral signal along the nanowires. The estimated $\mathrm{d}_{14}$ PE coefficient was about $8 \mathrm{pC} / \mathrm{N}$.

An exciting potential in cell promotion, stimulation, proliferation, and differentiation is accessible using the biocompatible and biodegradable PLLA PE polymer. Drawn PE PLLA rods, in contrast to non-drawn PLLA rods with no PE response, form higher callus in the intramedullary cavity of the feline tibia of cats, fracture healing improves. The finding of this research shows the effect of PE PLLA drawn in fracture fixation devices [133].

\subsection{Bio-Concern}

Because of ester bonding in PLA chains when exposed to water or microbial milieu, hydraulic degradation happens, which comes from a bulk erosion mechanism by random 
scission of the backbone [17,134], Ishi et al. demonstrated in vivo degradation behavior of PLLA fibers. The research team implanted the fibers in Wistar rats; after 12 weeks [89], they confirmed the complete dissociation of the fiber structure and decreased the degree of crystallinity and molecular weight by in vivo biodegradation.

PLA is mainly used for applications, e.g., drug delivery and TE, which require biodegradable properties [135]. PLA is among the well-known and long-standing synthetic biopolymers. It has been demonstrated that the PLLA slowly degrades when reacting with the water environment of tissue [136]. In a study by Bos et al. [137], high-molecular-weight specimens implanted on the back of a rat and their in vivo long-term degradation was studied. A decrease in molecular weight was observed in a 3-month period. Continuous mass loss was observed up to 26 weeks with no chronic, acute inflammatory reactions, and after 104 weeks, macrophages appeared to clean the remaining PLLA content.

Curry et al. fabricated a PE force sensor which is completely biodegradable for the first time by a heat compression, mechanical stretching, annealing process at $90^{\circ} \mathrm{C}$ for $8 \mathrm{~h}$. PLLA fibers were cut at a $45^{\circ}$ angle relative to the stretching direction to investigate the piezo properties. They incorporated molybdenum electrodes on PLLA film and encapsulated them with PLA to introduce a PLLA biodegradable implantable force/pressure sensor. The film was inserted into an incision below the mouse's diaphragm, and with each mouse breath under anesthesia, a clear signal was detected and correlated to sinusoidal force nearly $0.1 \mathrm{~N} / \mathrm{cm}^{-2}$. The best PE properties came from the drawing ratio in the range of 2.5-4.5, and the PE constant was approximately $11 \mathrm{pC} / \mathrm{N}$. They observed the complete degradation of PLLA film in the phosphate-buffered saline (PBS) at $74{ }^{\circ} \mathrm{C}$ after 56 days [85].

It has been clear that through the degradation process, crystalline phases last more while amorphous regions disgrace faster. Here, it is worth noting that the PLLA can last for 5.7 years, maintaining its good biocompatibility up to its complete decomposing [138].

\section{PLA Composites and Application}

By expanding the science fringes, PE properties have shown their critical role in various engineering fields. It is expected for their market value to reach from 20.35 billion in 2015 to USD 27.24 billion by 2020, growing at a high compound annual growth rate of $6.01 \%$ [139].

The electronics industry is one of the significant industries looking to utilize renewable materials for replacing rare-metal-based and non-recyclable products. Electronic devices consist of organic or inorganic materials interfacing with human/animal bodies. Bio-piezopolymers, which have no hazardous impact on the body, are the future of TE. They can function as sensors [140-142], actuators, in-vivo info processing systems, and biological collector signals [143-148]. PVDF is a chemically stable PE polymer with high piezo-, pyro- and ferroelectric properties $[17,57]$. Among the applications are transducers and sensors, human health monitoring systems, biomedical materials, polymeric electrolytes, and filtration membranes [91,130,131].

Portable and wearable PE nanogenerators (PENG), which can convert mechanical strain to electrical energy, are the attractive field of research in the literature. Wearable and implantable flexible PENG for physiological signal sensing and studying sleep quality are among the most anticipated areas of examinations. PVDF cable sensors or PVDF-sensorarray-integrated mattresses have been developed and can record cardiac and respiratory actions while the subject is in a lying posture $[90,149]$.

Other distinctive features include its small size, light weight, ease of use, low cost, portability, and the ability to harvest energy efficiently from heat [17], light [18], mechanical vibration [150], wind energy [67], sonic waves [149], fluidics [90], and bio-motions [135] present in the environment. The practicability of the PNGs is already verified by powering different devices such as light-emitting diodes (LEDs) [151], liquid crystal displays (LCDs) [152], speakers, watches [153], medical imaging [117], telecommunication, and ultrasonic devices [114]. 
For instance, it would be fascinating having muscles spread in a hosting material, such as in a bat's wing, to sense and actuate in the latter case. Little work has been conducted in the perspective mentioned above; electrospun muscles that find their actuation capability in environmental $\mathrm{pH}$ changes were successfully made of polyacrylonitrile [135].

As reviewed in [154], PLLA-based composites have been researched extensively in order to be applied in the field of orthopedic regenerative engineering $[155,156]$. Although PLA PE properties have been proven [64], the focus of the researchers has been on improving the suitability of the patches for the desired application, accompanied by no dynamic environment and without mentioning the contribution of PE properties of fillers or PLA itself.

\subsection{The Future Portrait of Tissue Regeneration}

As opposed to ferroelectric ceramics, ferroelectric polymers are profoundly flexible, biocompatible, and processable, making them exciting candidates for wearable and implantable electronics for human bodies. Relating to this, PVDF and its copolymer, because of their biocompatibility, high chemical resistance, light weight, flexibility, high PE properties, and economic considerations, are the surrogate choices to fabricate nanogenerators. The next revolution in PE properties emerged when decent PE materials such as Organic PE materials and synthetic polymers called "piezo polymers" were found [30,157-160].

In contrast to common PE materials such as lead zirconia titanate (PZT) [161] and polyvinylidene flurried (PVDF) [162], PLA is less studied, and thus there is a long way to go to utilize its properties. Despite most ceramic PE devices requiring an external foreign electrical or magnetic field, after fabrication, PLA asks for no electrical poling treatment to show the piezo-response from itself $[117,153]$.

In materials with PE performance, displacement is generated without an external electric field; regardless, there are barriers to control the stimulus [163]. The importance of the interface between the bioelectronic devices and human bodies highlights the biosafety concerns. The biodegradability of organic and synthetic materials is one of the greatly desired features, which should be considered to prevent the additional surgical procedure. With this in mind, biocompatible and biodegradable polymers, which are also environmentally friendly, are impressive materials $[17,24,85,164]$.

The process, which leads the biological PEs mainly mimicking, consists of stretching the intrinsic piezo materials that can degrade in similar body conditions. The benefit of $\mathrm{PE}$ in tissue regeneration might be because of the fact that polarized polymers show more significant protein adsorption and enhanced cellular adhesion and proliferation $[165,166]$.

Currently, the high demand for stretchable and wearable electronics has attracted lots of attention itself. Innovative stretchable PE materials convert the forms of energy to each other by bending repetitions, folding, or stretching without loss of performance and are highly beneficial in wearable and portable electronics such as touch screens, wearable sensors, military garment devices, and biomedical applications [167].

As a matter of composition, TPS, a promising biodegradable material with abundance, high ductility, and low cost, has drawn attention; hence, it is used to blend with PLA [168]. However, these two hydrophobic materials are incompatible, leading to phase separation [169]. Because TPS contains hydroxyl group-rich plasticizer and starch, it is highly hygroscopic and sensitive to moisture absorption when stored at a high temperature; this is a barrier to mat fabrication and causes poor mechanical properties and sticky surface [122].

\subsection{Tissue Engineering and Regenerative Medicine}

The main pillars of TE are cells, scaffolds, and biologically active signaling molecules. Artificial patches act to mimic the ECM and their biocompatibility with the appropriate fiber diameter and pore size to make cell attachment and migration possible. Sufficient surface area and surface chemistry to facilitate cell adhesion, growth, migration, and differentiation, robust mechanical properties, and a biodegradation rate similar to the regeneration rate of the tissue being engineered are the factors that should be considered [170]. 
Demanded power-based electric generators are top-rated in bio-applications because of they are lightweight to wear in addition to their in vivo performance despite lab-on-chip devices. Nanomaterial PEs can be integrated with composite polymer and fibers. However, a durable, flexible, and wearable power generator that can generate an adequate electric field from human motions must be produced [167].

Scaffolds manufactured from polymer-nanoparticle composites can be performed with two distinct strategies; first, incorporating the nanoparticles into the polymer matrix, and second, including instinct polymers [171]. Utilizing metal nanoparticles is more common because of their unique electrical, optical, and catalytic properties [172]. For instance, combining gold and silver nanoparticles and carbon nanotubes to various polymers in the ES process has been widely researched [171-173].

\subsubsection{PLA Composite}

As is evident in Figure 11, cultured murine C2C12 myoblast on electrospun PLLA fibers produced highly organized myotubes grown along the nanofibers [174]. ES can provide a way to fabricate dense and uniformly aligned packed skeletal muscle tissue, which greatly resembles the native skeletal muscle [175].

(a)

(c)

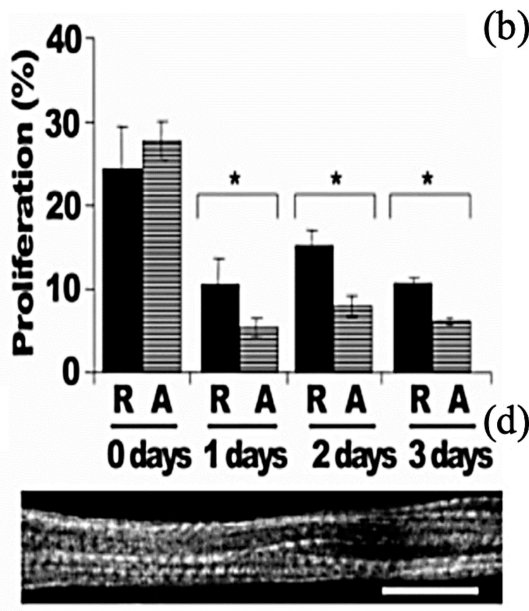

(e)

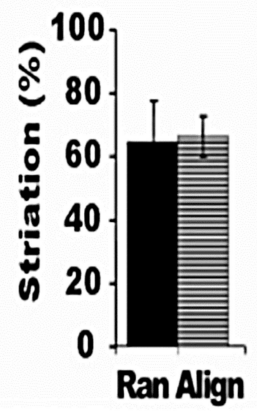

(b)

(f)
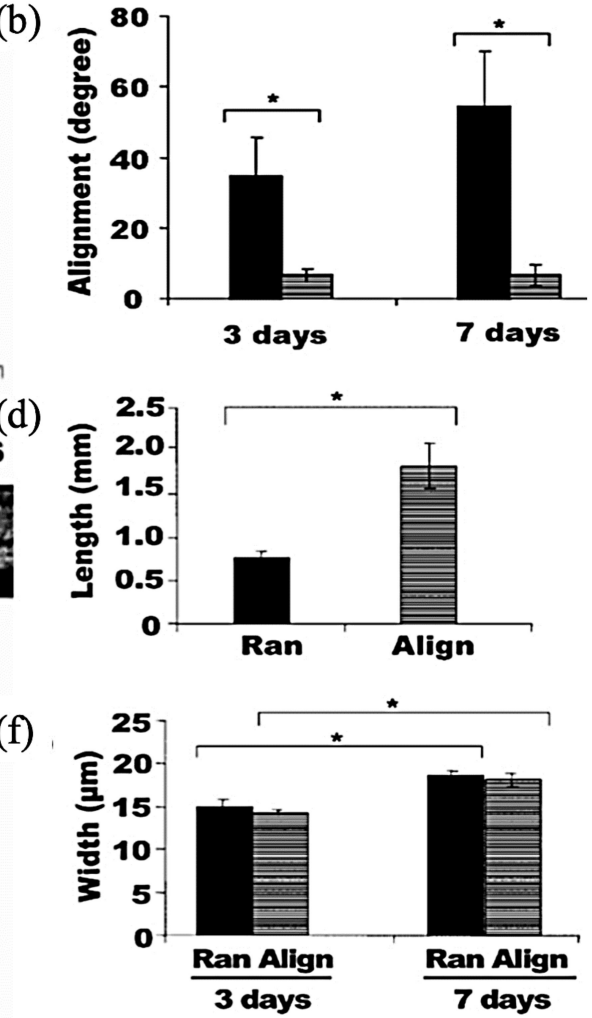

Figure 11. Quantification of myoblast proliferation and myotube striation on aligned nanofibrous scaffolds: (a) BrdU incorporation for cell proliferation (R, ran; A, align); (c) Immunofluorescence staining of anti-MHC showing a striated myotube on an aligned nanofibrous scaffold (scale bar, $20 \mu \mathrm{m})$; (e) Quantification of the percentage of striated cells after 7 days. Asterisks indicate a statistically significant difference $\left({ }^{*} p<0.05\right)$; (b) The angle of myotube alignment in reference to nanofiber direction; (d) Myotube length after 7 days; (f) Myotube width after 7 days. Asterisks indicate a statistically significant difference $\left.{ }^{*} p<0.05\right)$; Reproduced from [174], with permission from Nano Letter; American Chemical Society, 2006.

Freeman et al. [176] came up with PLLA gold-nanoparticle composites, and skeletal muscle TE was also investigated. This research concentrated on employing different proportions of gold nanoparticles in the PLLA matrix to study mechanical properties, 
electrical conductivity, and cellular behavior while lacking the ability to improve the fiber alignment and decrease the agglomeration of the conductive particles and solve the fiber fusion matter. The results show that although the cellular proliferation was low on their scaffolds, they showed that the Au Nps displayed no toxic effects; on the other hand, the mechanical properties of the stands were higher than skeletal muscles, which suggest that the lower Au NPs have to be used to match the mechanical properties of the tissue.

Schlatter et al. fabricated an electrospun PLA: Poly(glycerol sebacate) (PGS) composite and used a post-annealing process, showing an increase in fiber thickness and crystallinity percentage and an improvement in the mats' mechanical properties. On the other hand, they have demonstrated that neither the composition nor the annealing process improves the hydrophilicity of PLA considerably. Matrigel coating of the samples causes adhesion of cardiomyocytes to both PLA pure and composite samples. At the same time, it is demonstrated that this coating would act as a possible point to reform the shape of the cells from a spherulitic physique to a cylindrical shape. Finally, they established the vascularization formation in PLA versus PLA: PGS composite as a matter of diffusion [177].

Increasing the electroconductivity of polymeric materials is one of the requirements in the course of scaffold considerations. PANI is one of the promising materials to overcome this drawback. Although the PANI concentration increases electrical conductivity, its dose affects cytotoxicity, cell adhesion, and proliferation, as shown in Figure 12. PEG's hydrophilicity decreases cell adhesion and proliferation [178].
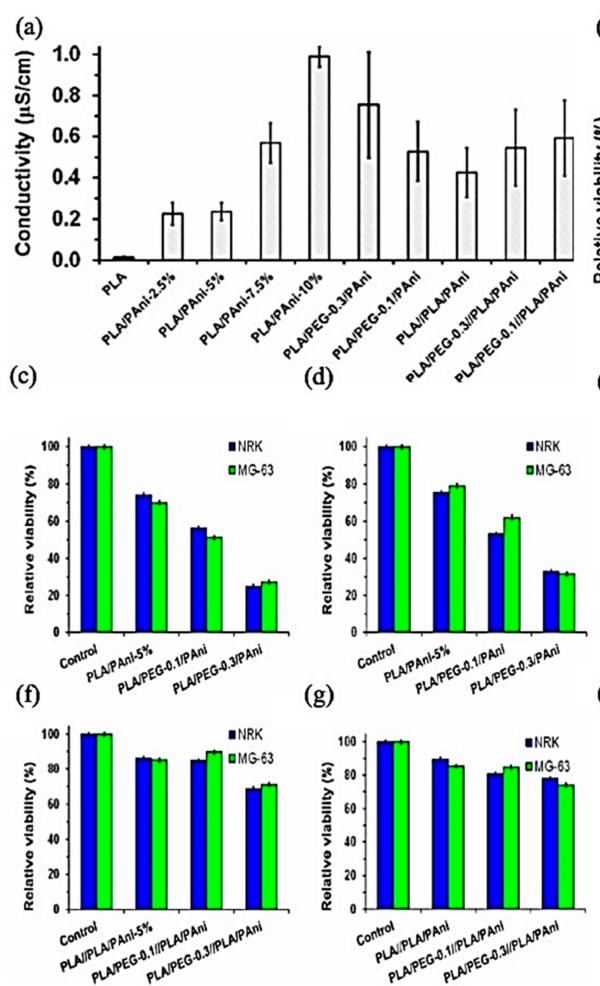

(b)

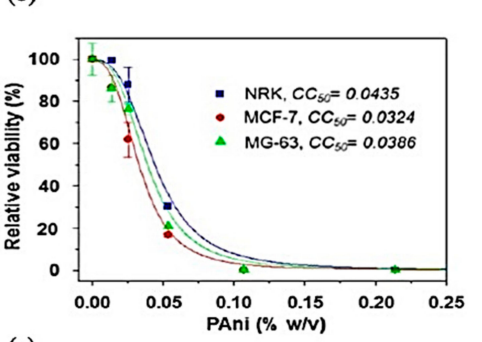

(e)

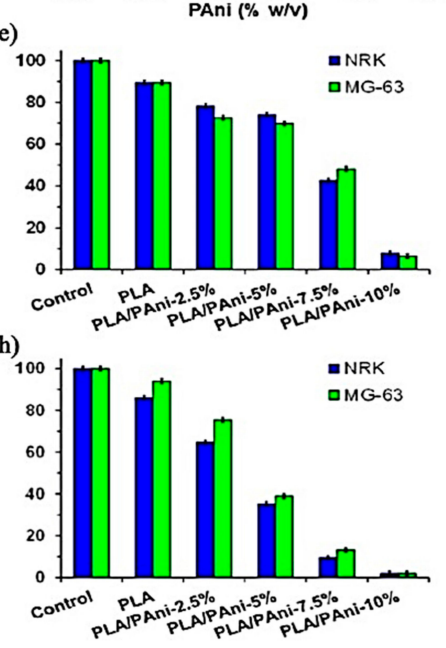

Figure 12. (a) Electrical conductivity of PLA, PLA/PAni, PLA/PEG/PAni, PLA//PLA/PAni, and PLA/PEG/ /PLA/PAni fibrous mats. (b) Cytotoxicity curve of PAni/DBSA for NRK, MCF-7, and MG-63 cells. (e,h) Biocompatibility of PLA/PAni fibers expressed as relative viability of NRK and MG-63 culture cells onto the fibrous mats after (e) $24 \mathrm{~h}$ (cell adhesion) and (h) $96 \mathrm{~h}$ (cell proliferation). Biocompatibility of (c,d) PLA/PEG/PAni and (f,g) PLA/PEG//PLA/PAni fibers expressed as relative viability of NRK and MG-63 culture cells onto the fibrous mats after (c,f) $24 \mathrm{~h}$ (cell adhesion) and (d,g) 96 h (cell proliferation); Adapted from [178], with permission from ACS Omega, 2019, https://pubs.acs.org/doi/abs/10.1021/acsomega.8b03411 (accessed on 25 August 2021), further permissions related to the material excerpted should be directed to the ACS. 
Studying a PLA: PEG: COLLAGEN composite revealed that increasing the PEG concentration causes a promotion in fiber diameter while it would increase cell death. The research also studied the impact of aligned mats on mechanical and biological issues; on the one hand, the alignment would increase the tensile strength and decrease the swelling ratio at the same time and, on the other hand, cause homogeneous cardiomyocyte cell growth, as it is visible in Figure 13. On the contrary, the addition of collagen improves both cell proliferation and viability [179].
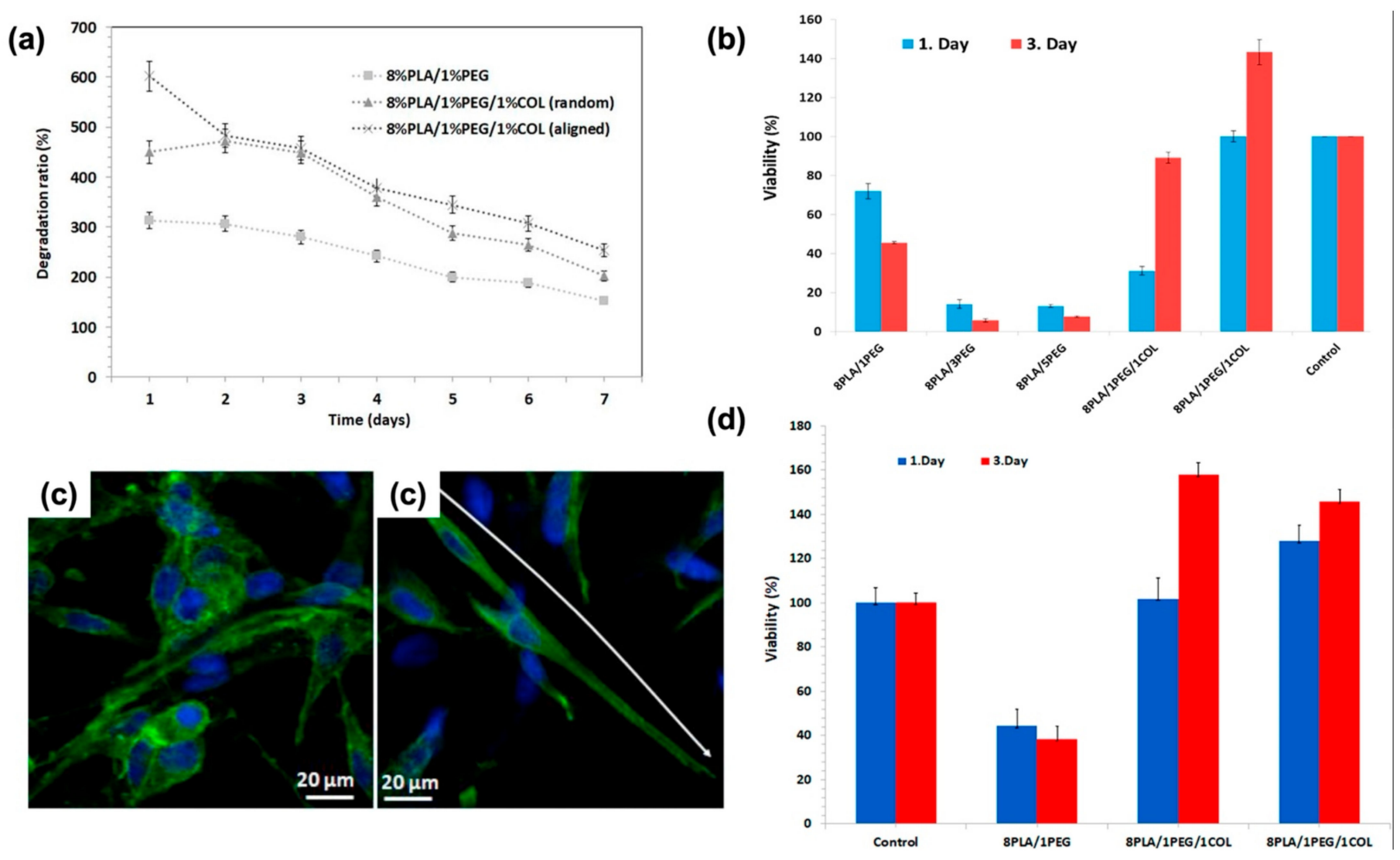

Figure 13. (a) The degradation behaviors of the patches after 7 days of incubation. (b) Cell viability graph of 2D H9C2 cells and nanofiber patches before and (d) after degradation. (c) Confocal images of random and (left) aligned (right) 8\%PLA/1\%PEG/1\%COL nanofiber patches; Adapted from [179], with permission from Polymer testing; Elsevier, 2020.

Modifying microfiber PLA scaffolds with various proteins was taken into consideration [180]; they coated collagen, gelatin, fibronectin, and Poly L lysine to the artificial mats, and their degradation rate up to 30 days was studied. An adult human cardiomyocyte adhesion and proliferation study revealed that the unmodified sample shows better cell adhesion, probably due to its rough topography. On the other hand, cytotoxicity results show us that the scaffolds do not exert any stress on the cells. The cell proliferation marker (Ki67) showed an improvement in proliferation kinetics, as shown in Figure 14.

\subsubsection{PLGA Composites}

PLGA is a biopolymer with no piezo properties but a low degradation time. Zheng et al. fabricated a fibrous composite consistent with PDLA, PLGA, and $\mathrm{CoFe}_{2} \mathrm{O}_{4}$ nanoparticles $(30 \mathrm{~nm})$. Beading is apparent in fabricated samples with lower concentrations related to viscosity. Thicker fabricated fibers in higher concentrations result in a more uniform morphology. The presence of magnetoelectric $\mathrm{CoFe}_{2} \mathrm{O}_{4}$ particles motivates the local electric field. The existence of amorphous PLGA causes no XRD peak; in addition, because of 
semi-crystalline PDLA components, peak appearance is possible in DSC. In this research, the piezo-response is just ascribed to the PDLA feature [181].

(a) \begin{tabular}{cccccccc}
\hline PROTEINS & TCP & UNMODIFIED & COLLAGEN & GELATIN & FIBRONECTIN & POLY L LYSINE \\
\hline IL-1 B & Y & Y & Y & Y & Y & Y \\
\hline PENTRAXIN3 & Y & Y & Y & Y & Y & Y \\
\hline TIMP1 & Y & Y & Y & Y & Y & Y \\
\hline VEGF & Y & Y & Y & Y & Y & Y \\
\hline ACTIVIN A & - & - & $Y$ & - & $Y$ & - \\
\hline PF4 & - & - & Y & - & - & - \\
\hline FGF-B & - & - & - & - & Y & - \\
PDGF AA & - & - & - & - & Y & - \\
\hline
\end{tabular}
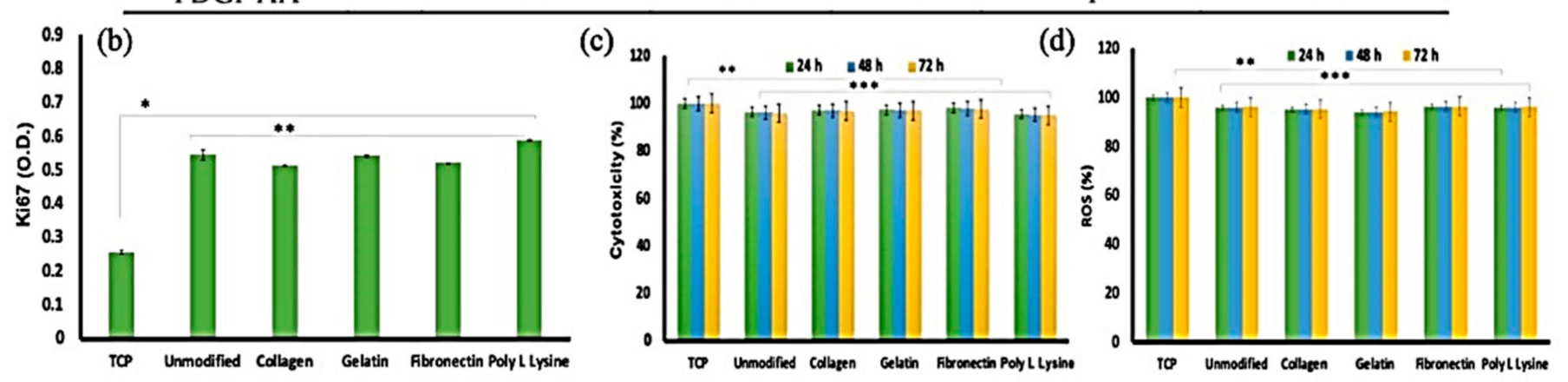

Figure 14. (a) Expressed proteins with a major role in cardiac fibroblast growth and differentiation. (b) Ki67, a cellular proliferation marker, was recorded at higher expression levels in cells cultured on the unmodified and protein-modified porous PLLA scaffolds than in the tissue culture plastic (TCP) substrates. The expression difference was a significant 2-fold increase in the fiber scaffolds than TCP. These observations support the enhanced compatibility the scaffolds share with the cells than conventional culture ware $\left(n=3,{ }^{*} p<0.05,{ }^{* *} p<0.01\right)$. (c) Cytocompatibility and reactive oxygen species (ROS) generation analysis of AHCF cultured on unmodified and protein-functionalized PLLA scaffolds. (c) No significant toxicity was observed with any of the scaffold variants. AHCF cultured on TCP were used as positive controls. (d) The AHCF cells cultured on the scaffolds did not show any noticeable ROS production, providing evidence that the scaffolds do not exert any stress on cells $\left(n=3,{ }^{* *} p<0.01,{ }^{* *} p<0.001\right)$; Adapted from [180], with permission from Polymers; MDPI, 2020.

Khan et al. seeded the human-induced pluripotent stem cells cardiomyocytes into the electrospun polylactide-co-glycolide (PLGA). They fabricated $50 \mu \mathrm{m}$-thick aligned nanofibrous scaffolds and compared the outcome against conventional tissue culture plastic surfaces. The outcomes from this research revealed that the scaffolds have the potential to align the CMs and provoke functionality changes of Calcium transients and gene expression through the appropriate stiffness of the mats [182].

Taking the PLGA and Carbon Nanofiber (CNF) composites to account, increasing the CNF content caused an enhancement in the conductivity and cytocompatibility of PLGA, in addition to cardiomyocyte adhesion and proliferation improvement. As shown in Figure 15, this study revealed an increase in the density of cardiomyocytes with an increase in CNF up to 25:75 wt.\% PLGA: CNFs [183].

Asiri et al. fabricaterd an aligned $20 \mu \mathrm{m}$ wide patter of $100 \mathrm{~nm}$ CNFs on the surface of PLGA with a 50:50 PGA: PLA weight ratio.They demonstrated that, on the one hand, the alignment of $\mathrm{CNF}$ increases the density of cardiomyocytes, and on the other hand, it promotes the longitudinal conductivity to $0.1 \mathrm{~S} / \mathrm{m}$ and decreases the horizontal conductivity to $0.0025 \mathrm{~S} / \mathrm{m}$ compared to randomly oriented fibers; these conductivities are similar to natural heart tissue [184].

In research from Gelmi and colleagues, they chlorine-doped PPy deposited on electrospun PLGA fibers and made a 3D and electrically conductive scaffold. They confirmed the biocompatibility of these scaffolds using cardiac progenitor cells and iPSCs. Later, using PPy, they coated PLGA to make a biocompatible EA patch for cardiogenic differentiation under electromechanical stimulation [185]. 

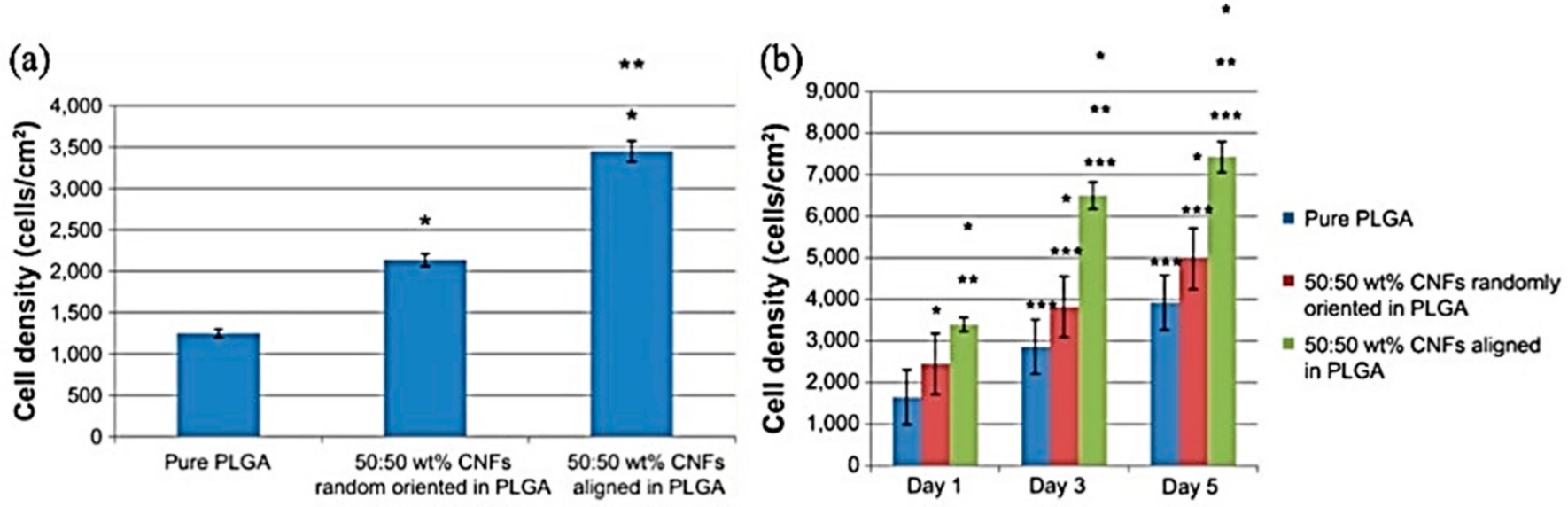

Figure 15. (a,b) Increased cardiomyocyte adhesion on aligned CNFs compared with randomly oriented CNFs in PLGA composites, (a) The adhesion time was $4 \mathrm{~h}$. Seeding density 3500 cells $/ \mathrm{cm} 2$. Data shown as the mean \pm standard error of the mean $(n=3) .{ }^{*} p<0.01$ compared with pure PLGA and ${ }^{* *} p<0.01$ compared with $50: 50 \mathrm{wt} \%$ CNFs randomly oriented in PLGA, (b) Seeding density 3500 cells $/ \mathrm{cm} 2$. Data shown as the mean \pm standard error of the mean $(n=3) .{ }^{*} p<0.01$ compared with pure PLGA at respective time period; ${ }^{* *} p<0.01$ compared with $50: 50 \mathrm{wt} \%$ randomly oriented CNFs in PLGA at respective time period; ${ }^{* * *} p<0.01$ compared with previous time period, same sample; Adapted from [183], with permission from International Journal of Nanomedicine; Dove Medical Press, 2014.

Furthermore, 3D PLGA-PANI aligned fibers were investigated by Hsiao et al. for the synchronous beating of cardiomyocytes. The fabricated scaffold increased the gap junction protein expression (Cx43) and troponin T. Isolated cell clusters with synchronous beatings formed from cardiomyocytes. The HCL-doped PANI promoted electrical conductivity, aroused positively charged cell membrane proteins, and advanced cell adhesion [186].

To yield electrically conductive hydrogels, attempts at incorporating PANI with different hydrogel and polymers have been triggered recently. Cui et al. fabricated a hydrogel composed of polylactide-poly(ethylene glycol)-polylactide (PLA-PEG-PLA) copolymer coated with tetra aniline (with carboxylate modification) to culture cardiomyocytes, fibroblasts, and osteoblasts. Applied electrical stimulation to the cultured cells on samples enhanced cell proliferation $[187,188]$.

\section{Conclusions}

ES was marked as the best procedure to induce PE in PLA ECM mimicking mats among the numerous fabrication procedures. This was attributed to the high shear force applied to the chains that stimulate $\mathrm{C}=\mathrm{O}$ dipoles to be oriented even in an amorphous structure. Although PLA was not a ferroelectric polymer, it showed PE, even in an amorphous state while inducing even a partially long-range ordering of the chains through thermo and/or mechanical work, which ought to increase the PE outcome. Regarding the fabrication of interconnected porous mats, in addition to what has already been denoted in the literature, it was shown in the above-discussed script that a micro-aligned mat, or in a better mode, nanoscale fibers had a tremendous potential to be used as artificial organs or at least a base for migration of the immature cells to the cells which were dead or could not perform their duty. The origin of the PE was described based on a non-centrosymmetric structure, and PLA had this non-centrosymmetry structure even in its amorphous state due to its chiral conformation. Tolerating the piezoelectric outcome required a semicrystalline state, which was induced by various PLA crystalline phases of $\alpha, \alpha^{\prime}, \beta$, and $\gamma$, all showing the PE within the lack of centrosymmetric. Another perspective that should be taken to account was the preferential crystalline planes; any texture induced by mechanical process improved the piezoelectric performance, as evidenced by 2D XRD narrations. Coming to the point, PLA biomaterial is going to be used in numerous aspects of TE, and numerous efforts have been made to improve PLA's hydrophilicity; however, it has been observed that it is not that essential for cell growth compared to tolerating its mechanical properties, 
such as its brittleness and stiffness, to be used in TE applications. Since the activation and use of the $P$ requires a type of applied pressure or mechanical work to scaffolds, the mat deformability is a matter of future attention that should be tuned simultaneously with the PE outcome.

Author Contributions: A.F., A.Z.-H., H.R.A., L.T. and E.M. made a significant contribution to the work reported, whether that is in the conception, study design, execution, acquisition of data, analysis and interpretation, or in all these areas; took part in drafting, revising or critically reviewing the article; gave final approval of the version to be published; have agreed on the journal to which the article has been submitted; and agree to be accountable for all aspects of the work. All authors have read and agreed to the published version of the manuscript.

Funding: Part of the research reported in this paper was supported by National Institute of Dental \& Craniofacial Research of the National Institutes of Health under award number R15DE027533, 1R56 DE029191-01A1 and 3R15DE027533-01A1W1. The content is solely the responsibility of the authors and does not necessarily represent the official views of the National Institutes of Health.

Institutional Review Board Statement: Not applicable.

Informed Consent Statement: Not applicable.

Data Availability Statement: The raw/processed data required to reproduce these findings cannot be shared at this time as the data also form part of an ongoing study.

Acknowledgments: Ebrahim Mostafavi would like to acknowledge the support from the National Institute of Biomedical Imaging and Bioengineering (5T32EB009035).

Conflicts of Interest: The authors declare no conflict of interest.

\section{References}

1. Zhu, J.; Jia, L.; Huang, R. Electrospinning polyl-lactic acid piezoelectric ordered porous nanofibers for strain sensing and energy harvesting. J. Mater. Sci. Mater. Electron. 2017, 28, 12080-12085. [CrossRef]

2. Jean-Mistral, C.; Basrour, S.; Chaillout, J.-J. Comparison of electroactive polymers for energy scavenging applications. Smart Mater. Struct. 2010, 19, 85012. [CrossRef]

3. Cai, G.; Liu, W.; He, Y.; Huang, J.; Duan, L.; Xiong, J.; Liu, L.; Wang, D. Recent advances in kartogenin for cartilage regeneration. J. Drug Target. 2019, 27, 28-32. [CrossRef] [PubMed]

4. Salzmann, G.M.; Sah, B.-R.; Schmal, H.; Niemeyer, P.; Sudkamp, N.P. Microfracture for Treatment of Knee Cartilage Defects in Children and Adolescents. Pediatr. Rep. 2012, 4, 82-84. [CrossRef]

5. Wang, C.; Yue, H.; Huang, W.; Lin, X.; Xie, X.; He, Z.; He, X.; Liu, S.; Bai, L.; Lu, B.; et al. Cryogenic 3D printing of heterogeneous scaffolds with gradient mechanical strengths and spatial delivery of osteogenic peptide/ $\{$ TGF $\}-\beta 1$ for osteochondral tissue regeneration. Biofabrication 2020, 12, 25030. [CrossRef]

6. Li, Y.; Liu, Y.; Xun, X.; Zhang, W.; Xu, Y.; Gu, D. Three-Dimensional Porous Scaffolds with Biomimetic Microarchitecture and Bioactivity for Cartilage Tissue Engineering. ACS Appl. Mater. Interfaces 2019, 11, 36359-36370. [CrossRef]

7. Lee, K.; Chen, Y.; Li, X.; Wang, Y.; Kawazoe, N.; Yang, Y.; Chen, G. Solution viscosity regulates chondrocyte proliferation and phenotype during 3D culture. J. Mater. Chem. B 2019, 7,7713-7722. [CrossRef]

8. Zhao, D.; Zhu, T.; Li, J.; Cui, L.; Zhang, Z.; Zhuang, X.; Ding, J. Polylactic-co-glycolic acid-based composite bone-substitute materials. Bioact. Mater. 2021, 6, 346-360. [CrossRef]

9. Huang, B.J.; Hu, J.C.; Athanasiou, A.K. Cell-based tissue engineering strategies used in the clinical repair of articular cartilage. Biomaterials 2016, 98, 1-22. [CrossRef]

10. Putri, N.R.E.; Wang, X.; Chen, Y.; Li, X.; Kawazoe, N.; Chen, G. Preparation of PLGA-collagen hybrid scaffolds with controlled pore structures for cartilage tissue engineering. Prog. Nat. Sci. Mater. Int. 2020, 30, 642-650. [CrossRef]

11. Vykhodtseva, N.; McDannold, N.; Hynynen, K. Progress and problems in the application of focused ultrasound for blood-brain barrier disruption. Ultrasonics 2008, 48, 279-296. [CrossRef]

12. Yazdanpanah, S.; Rabiee, M.; Tahriri, M.; Abdolrahim, M.; Tayebi, L. Glycated hemoglobin-detection methods based on electrochemical biosensors. TrAC Trends Anal. Chem. 2015, 72, 53-67. [CrossRef]

13. Robinson, A.J.; Pérez-Nava, A.; Ali, S.C.; González-Campos, J.B.; Holloway, J.L.; Cosgriff-Hernandez, E.M. Comparative analysis of fiber alignment methods in electrospinning. Matter 2021, 4, 821-844. [CrossRef]

14. Prokhorov, E.; Bárcenas, G.L.; Sánchez, B.L.E.; Franco, B.; Padilla-Vaca, F.; Landaverde, M.A.H.; Limón, J.M.Y.; López, R.A. Chitosan-BaTiO3 nanostructured piezopolymer for tissue engineering. Colloids Surfaces B Biointerfaces 2020, 196, 111296. [CrossRef]

15. Meira, R.M.; Correia, D.M.; Ribeiro, S.; Costa, P.; Gomes, A.C.; Gama, F.M.; Lanceros-Méndez, S.; Ribeiro, C. Ionic-Liquid-Based Electroactive Polymer Composites for Muscle Tissue Engineering. ACS Appl. Polym. Mater. 2019, 1, 2649-2658. [CrossRef] 
16. Montero, P.; Flandes-Iparraguirre, M.; Musquiz, S.; Araluce, M.P.; Plano, D.; Sanmartín, C.; Orive, G.; Gavira, J.J.; Prosper, F.; Mazo, M.M. Cells, Materials, and Fabrication Processes for Cardiac Tissue Engineering. Front. Bioeng. Biotechnol. $2020,8,955$. [CrossRef]

17. Nair, L.S.; Laurencin, C.T. Biodegradable polymers as biomaterials. Prog. Polym. Sci. 2007, 32, 762-798. [CrossRef]

18. Hickey, D.J.; Ercan, B.; Sun, L.; Webster, T.J. Adding MgO nanoparticles to hydroxyapatite-PLLA nanocomposites for improved bone tissue engineering applications. Acta Biomater. 2015, 14, 175-184. [CrossRef]

19. Curie, J.; Curie, P. Développement par compression de l'électricité polaire dans les cristaux hémièdres à faces inclinées. Bull. La Société Minéralogique Fr. 1880, 3, 90-93. [CrossRef]

20. Panda, P.K. Review: Environmental friendly lead-free piezoelectric materials. J. Mater. Sci. 2009, 44, 5049-5062. [CrossRef]

21. Learning, L.; Hill, L. Chapter 2: The Big Picture; Oklahoma State University: Stillwater, OK, USA, 2019.

22. Mason, W.P.; Thurston, R.N.; Arnold, W.; Eisenmenger, W. Physical Acoustics; Academic Press: New York, NY, USA, 1976; Volume 12.

23. Ou, X.; Cakmak, M. Influence of biaxial stretching mode on the crystalline texture in polylactic acid films. Polymer 2008, 49, 5344-5352. [CrossRef]

24. Feig, V.R.; Tran, H.; Bao, Z. Biodegradable Polymeric Materials in Degradable Electronic Devices. ACS Cent. Sci. 2018, 4, 337-348. [CrossRef]

25. Fukada, E. Piezoelectricity of biopolymers. Biorheology 1995, 32, 593-609. [CrossRef]

26. Ponnamma, D.; Ogunleye, G.J.; Sharma, P.; AlMaadeed, M.A. 12- Piezo- and Thermoelectric Materials from Biopolymer Composites. In Biopolymer Composites in Electronics; Sadasivuni, K.K., Ponnamma, D., Kim, J., Cabibihan, J.-J., AlMaadeed, M.A., Eds.; Elsevier: Amsterdam, The Netherlands, 2019; pp. 333-352. [CrossRef]

27. Smyth, M.; Poursorkhabi, V.; Mohanty, A.K.; Gregori, S.; Misra, M. Electrospinning highly oriented and crystalline polylactic acid fiber mats. J. Mater. Sci. 2014, 49, 2430-2441. [CrossRef]

28. Nunes-Pereira, J.; Costa, P.; Lanceros-Mendez, S. 3.9 Piezoelectric Energy Production. In Comprehensive Energy Systems; Dincer, I., Ed.; Elsevier: Oxford, UK, 2018; pp. 380-415. [CrossRef]

29. Yang, L.; Li, X.; Allahyarov, E.; Taylor, P.L.; Zhang, Q.M.; Zhu, L. Novel polymer ferroelectric behavior via crystal isomorphism and the nanoconfinement effect. Polymer 2013, 54, 1709-1728. [CrossRef]

30. Kepler, R.G.; Anderson, R.A. Ferroelectricity in polyvinylidene fluoride. J. Appl. Phys. 1978, 49, 1232-1235. [CrossRef]

31. Akbarzadeh, R.; Yousefi, A.-M. Effects of processing parameters in thermally induced phase separation technique on porous architecture of scaffolds for bone tissue engineering. J. Biomed. Mater. Res. Part B Appl. Biomater. 2014, 102, 1304-1315. [CrossRef] [PubMed]

32. Lee, K.; Silva, E.A.; Mooney, D.J. Growth factor delivery-based tissue engineering: General approaches and a review of recent developments. J. R. Soc. Interface. 2011, 8, 153-170. [CrossRef] [PubMed]

33. Huang, C.-Y.; Hu, K.-H.; Wei, Z.-H. Comparison of cell behavior on pva/pva-gelatin electrospun nanofibers with random and aligned configuration. Sci. Rep. 2016, 6, 37960. [CrossRef]

34. Taherkhani, S.; Moztarzadeh, F. Fabrication of a polye-caprolactone/starch nanocomposite scaffold with a solvent-casting/saltleaching technique for bone tissue engineering applications. J. Appl. Polym. Sci. 2016, 133. [CrossRef]

35. Roshandel, M.; Dorkoosh, F. Cardiac tissue engineering, biomaterial scaffolds, and their fabrication techniques. Polym. Adv. Technol. 2021, 32, 2290-2305. [CrossRef]

36. Zheng, H.-D.; Liu, L.-L.; Deng, C.-L.; Shi, Z.-F.; Ning, C.-Y. Mechanical properties of AM Ti6Al4V porous scaffolds with various cell structures. Rare Met. 2019, 38, 561-570. [CrossRef]

37. Ngo, T.D.; Kashani, A.; Imbalzano, G.; Nguyen, K.T.Q.; Hui, D. Additive manufacturing 3D printing: A review of materials, methods, applications and challenges. Compos. Part B Eng. 2018, 143, 172-196. [CrossRef]

38. Liu, C.; Xia, Z.; Czernuszka, J.T. Design and Development of Three-Dimensional Scaffolds for Tissue Engineering. Chem. Eng. Res. Des. 2007, 85, 1051-1064. [CrossRef]

39. Zhang, L.; Morsi, Y.; Wang, Y.; Li, Y.; Ramakrishna, S. Review scaffold design and stem cells for tooth regeneration. Jpn. Dent. Sci. Rev. 2013, 49, 14-26. [CrossRef]

40. Cavo, M.; Serio, F.; Kale, N.R.; D'Amone, E.; Gigli, G.; del Mercato, L.L. Electrospun nanofibers in cancer research: From engineering of: From vitro 3D cancer models to therapy. Biomater. Sci. 2020, 8, 4887-4905. [CrossRef]

41. Chi, H.; Xue, J.; Zhang, C.; Chen, H.; Li, L.; Qin, Y. High Pressure Treatment for Improving Water Vapour Barrier Properties of Polylactic acid/Ag Nanocomposite Films. Polymers 2018, 10, 1011. [CrossRef]

42. Mohan, D.; Arris, F.A.; Sajab, M.S.; Mansor, N.N. Facile Synthesis of 3D Printed Tailor-Shape Electrode PLA-GnP for Electrochemical Sensing. Eng. Proc. 2021, 4, 34. [CrossRef]

43. Stout, D.A.; Basu, B.; Webster, T.J. Polylactic-co-glycolic acid: Carbon nanofiber composites for myocardial tissue engineering applications. Acta Biomater. 2011, 7, 3101-3112. [CrossRef]

44. Araki, J.; Miyayama, M. Wet spinning of cellulose nanowhiskers; fiber yarns obtained only from colloidal cellulose crystals. Polymer 2020, 188, 122116. [CrossRef]

45. Wu, S.; Zhou, R.; Zhou, F.; Streubel, P.N.; Chen, S.; Duan, B. Electrospun thymosin Beta-4 loaded PLGA/PLA nanofiber/ microfiber hybrid yarns for tendon tissue engineering application. Mater. Sci. Eng. C 2020, 106, 110268. [CrossRef] 
46. Liu, Y.-J.; Tan, J.; Yu, S.-Y.; Yousefzadeh, M.; Lyu, T.; Jiao, Z.-W.; Li, H.; Ramakrishna, S. High-efficiency preparation of polypropylene nanofiber by melt differential centrifugal electrospinning. J. Appl. Polym. Sci. 2020, 137, 48299. [CrossRef]

47. Kamin, Z.; Abdulrahim, N.; Misson, M.; Chiam, C.K.; Sarbatly, R.; Krishnaiah, D.; Bono, A. Use of melt blown polypropylene nanofiber templates to obtain homogenous pore channels in glycidyl methacrylate/ethyl dimethacrylate-based monoliths. Chem. Eng. Commun. 2021, 208, 661-672. [CrossRef]

48. Tan, N.P.B.; Paclijan, S.S.; Ali, H.N.M.; Hallazgo, C.M.J.S.; Lopez, C.J.F.; Ebora, Y.C. Solution Blow Spinning SBS Nanofibers for Composite Air Filter Masks. ACS Appl. Nano Mater. 2019, 2, 2475-2483. [CrossRef]

49. Bazrafshan, V.; Saeidi, A.; Mousavi, A. The effect of different process parameters on polyamide 66 nano fiber by force spinning method. AIP Conf. Proc. 2020, 2205, 20008. [CrossRef]

50. Hou, Y.; Cheng, L.; Zhang, Y.; Yang, Y.; Deng, C.; Yang, Z.; Chen, Q.; Wang, P.; Zheng, L. Electrospinning of Fe/SiC Hybrid Fibers for Highly Efficient Microwave Absorption. ACS Appl. Mater. Interfaces 2017, 9, 7265-7271. [CrossRef] [PubMed]

51. Reneker, D.H.; Yarin, A.L. Electrospinning jets and polymer nanofibers. Polymer 2008, 49, 2387-2425. [CrossRef]

52. Tomaszewski, W.; Swieszkowski, W.; Szadkowski, M.; Kudra, M.; Ciechanska, D. Simple methods influencing on properties of electrospun fibrous mats. J. Appl. Polym. Sci. 2012, 125, 4261-4266. [CrossRef]

53. Castro, K.C.; Campos, M.G.N.; Mei, L.H.I. Hyaluronic acid electrospinning: Challenges, applications in wound dressings and new perspectives. Int. J. Biol. Macromol. 2021, 173, 251-266. [CrossRef]

54. Baji, A.; Mai, Y.-W.; Wong, S.-C.; Abtahi, M.; Chen, P. Electrospinning of polymer nanofibers: Effects on oriented morphology, structures and tensile properties. Compos. Sci. Technol. 2010, 70, 703-718. [CrossRef]

55. Ero-Phillips, O.; Jenkins, M.; Stamboulis, A. Tailoring Crystallinity of Electrospun Plla Fibres by Control of Electrospinning Parameters. Polymers 2012, 4, 1331-1348. [CrossRef]

56. Jin-Shan, T.; Yun-Ze, L.; Meng-Meng, L. Preparation of Aligned Polymer Micro/Nanofibres by Electrospinning. Chin. Phys. Lett. 2008, 25, 3067-3070. [CrossRef]

57. Singhvi, M.S.; Zinjarde, S.S.; Gokhale, D.V. Polylactic acid: Synthesis and biomedical applications. J. Appl. Microbiol. 2019, 127, 1612-1626. [CrossRef]

58. Ito, S.; Imoto, K.; Takai, K.; Kuroda, S.; Kamimura, Y.; Kataoka, T.; Kawai, N.; Date, M.; Fukada, E.; Tajitsu, Y. Sensing Using Piezoelectric Chiral Polymer Fiber. Jpn. J. Appl. Phys. 2012, 51, 09LD16. [CrossRef]

59. Morvan, J.; Buyuktanir, E.; West, J.L.; Jákli, A. Highly piezoelectric biocompatible and soft composite fibers. Appl. Phys. Lett. 2012, 100, 63901. [CrossRef]

60. Morvan, J. Highly Piezoelectric Soft Composite Fibers; Kent State University: Kent, OH, USA, 2012.

61. Luo, C.J.; Nangrejo, M.; Edirisinghe, M. A novel method of selecting solvents for polymer electrospinning. Polymer 2010, 51, 1654-1662. [CrossRef]

62. Wannatong, L.; Sirivat, A.; Supaphol, P. Effects of solvents on electrospun polymeric fibers: Preliminary study on polystyrene. Polym. Int. 2004, 53, 1851-1859. [CrossRef]

63. Zhao, G.; Huang, B.; Zhang, J.; Wang, A.; Ren, K.; Wang, Z.L. Electrospun Polyl-Lactic Acid Nanofibers for Nanogenerator and Diagnostic Sensor Applications. Macromol. Mater. Eng. 2017, 302, 1600476. [CrossRef]

64. Lee, S.J.; Arun, A.P.; Kim, K.J. Piezoelectric properties of electrospun polyl-lactic acid nanofiber web. Mater. Lett. 2015, 148, 58-62. [CrossRef]

65. Ma, H.; Su, W.; Tai, Z.; Sun, D.; Yan, X.; Liu, B.; Xue, Q. Preparation and cytocompatibility of polylactic acid/hydroxyapatite/graphene oxide nanocomposite fibrous membrane. Chin. Sci. Bull. 2012, 57, 3051-3058. [CrossRef]

66. Nampoothiri, K.M.; Nair, N.R.; John, R.P. An overview of the recent developments in polylactide PLA research. Bioresour. Technol. 2010, 101, 8493-8501. [CrossRef]

67. Södergård, A.; Stolt, M. Properties of lactic acid based polymers and their correlation with composition. Prog. Polym. Sci. 2002, 27, 1123-1163. [CrossRef]

68. Lim, L.-T.; Auras, R.; Rubino, M. Processing technologies for polylactic acid. Prog. Polym. Sci. 2008, 33, 820-852. [CrossRef]

69. Tsuji, H. Polylactide Stereocomplexes: Formation, Structure, Properties, Degradation, and Applications. Macromol. Biosci. 2005, 5, 569-597. [CrossRef]

70. Liu, G.; Zhang, X.; Wang, D. Tailoring Crystallization: Towards High-Performance Polylactic acid. Adv. Mater. 2014, 26 , 6905-6911. [CrossRef]

71. Cartier, L.; Okihara, T.; Lotz, B. Triangular Polymer Single Crystals: Stereocomplexes, Twins, and Frustrated Structures. Macromolecules 1997, 30, 6313-6322. [CrossRef]

72. Tsuji, H.; Ikada, Y. Stereocomplex formation between enantiomeric polylactic acids. 9. Stereocomplexation from the melt, Macromolecules 1993, 26, 6918-6926. [CrossRef]

73. Park, H.-S.; Hong, C.-K. Relationship between the stereocomplex crystallization behavior and mechanical properties of PLLA/PDLA blends. Polymers 2021, 13, 1851. [CrossRef]

74. Tsuji, H.; Hyon, S.H.; Ikada, Y. Stereocomplex formation between enantiomeric polylactic acids. 3. Calorimetric studies on blend films cast from dilute solution. Macromolecules 1991, 24, 5651-5656. [CrossRef]

75. Zhang, J.; Tashiro, K.; Tsuji, H.; Domb, A.J. Investigation of Phase Transitional Behavior of Polyl-lactide/Polyd-lactide Blend Used to Prepare the Highly-Oriented Stereocomplex. Macromolecules 2007, 40, 1049-1054. [CrossRef] 
76. Fujita, M.; Sawayanagi, T.; Abe, H.; Tanaka, T.; Iwata, T.; Ito, K.; Fujisawa, T.; Maeda, M. Stereocomplex Formation through Reorganization of Polyl-lactic acid and Polyd-lactic acid Crystals. Macromolecules 2008, 41, 2852-2858. [CrossRef]

77. Xiong, Z.; Liu, G.; Zhang, X.; Wen, T.; de Vos, S.; Joziasse, C.; Wang, D. Temperature dependence of crystalline transition of highly-oriented polyl-lactide/polyd-lactide blend: In-situ synchrotron X-ray scattering study. Polymer 2013, 54, 964-971. [CrossRef]

78. Na, B.; Zhu, J.; Lv, R.; Ju, Y.; Tian, R.; Chen, B. Stereocomplex Formation in Enantiomeric Polylactides by Melting Recrystallization of Homocrystals: Crystallization Kinetics and Crystal Morphology. Macromolecules 2014, 47, 347-352. [CrossRef]

79. Auras, R.A.; Lim, L.-T.; Selke, S.E.M.; Tsuji, H. (Eds.) Wiley Series on Polymer Engineering and Technology. In Poly Lactic Acid: Synthesis, Structures, Properties, Processing, and Applications; Wiley: Hoboken, NJ, USA, 2010.

80. Gupta, B.; Revagade, N.; Hilborn, J. Polylactic acid fiber: An overview. Prog. Polym. Sci. 2007, 32, 455-482. [CrossRef]

81. Tsuji, H.; Ikada, Y. Stereocomplex formation between enantiomeric polylactic acids. XI. Mechanical properties and morphology of solution-cast films. Polymer 1999, 40, 6699-6708. [CrossRef]

82. Fukushima, K.; Kimura, Y. An efficient solid-state polycondensation method for synthesizing stereocomplexed polylactic acids with high molecular weight. J. Polym. Sci. Part A Polym. Chem. 2008, 46, 3714-3722. [CrossRef]

83. Garlotta, D. A Literature Review of PolyLactic Acid. J. Polym. Environ. 2001, 9, 63-84. [CrossRef]

84. Rasal, R.M.; Janorkar, A.V.; Hirt, D.E. Polylactic acid modifications. Prog. Polym. Sci. 2010, 35, 338-356. [CrossRef]

85. Middleton, J.C.; Tipton, A.J. Synthetic biodegradable polymers as orthopedic devices. Biomaterials 2000, 21, 2335-2346. [CrossRef]

86. Takarada, J.; Kataoka, T.; Yamamoto, K.; Nakiri, T.; Kato, A.; Yoshida, T.; Tajitsu, Y. Fundamental Study on Vibration in Edge Face of Piezoelectric Chiral Polymer Film. Jpn. J. Appl. Phys. 2013, 52, 09KE01. [CrossRef]

87. Yazdimamaghani, M.; Razavi, M.; Vashaee, D.; Moharamzadeh, K.; Boccaccini, A.R.; Tayebi, L. Porous magnesium-based scaffolds for tissue engineering. Mater. Sci. Eng. C 2017, 71, 1253-1266. [CrossRef]

88. Nair, L.S.; Laurencin, C.T. Polymers as Biomaterials for Tissue Engineering and Controlled Drug Delivery. In Tissue Engineering I; Lee, K., Kaplan, D., Eds.; Springer: Berlin/Heidelberg, Germany, 2006; pp. 47-90. [CrossRef]

89. Lalwani, G.; Henslee, A.M.; Farshid, B.; Parmar, P.; Lin, L.; Qin, Y.-X.; Kasper, F.K.; Mikos, A.G.; Sitharaman, B. Tungsten disulfide nanotubes reinforced biodegradable polymers for bone tissue engineering. Acta Biomater. 2013, 9, 8365-8373. [CrossRef]

90. van de Velde, K.; Kiekens, P. Biopolymers: Overview of several properties and consequences on their applications. Polym. Test 2002, 21, 433-442. [CrossRef]

91. Sencadas, V.; Ribeiro, C.; Heredia, A.; Bdikin, I.K.; Kholkin, A.L.; Lanceros-Mendez, S. Local piezoelectric activity of single polyL-lactic acid PLLA microfibers. Appl. Phys. A 2012, 109, 51-55. [CrossRef]

92. Jazayeri, H.E.; Lee, S.-M.; Kuhn, L.; Fahimipour, F.; Tahriri, M.; Tayebi, L. Polymeric scaffolds for dental pulp tissue engineering: A review. Dent. Mater. 2020, 36, e47-e58. [CrossRef]

93. Xu, H.; Teng, C.; Yu, M. Improvements of thermal property and crystallization behavior of PLLA based multiblock copolymer by forming stereocomplex with PDLA oligomer. Polymer 2006, 47, 3922-3928. [CrossRef]

94. Lovell, C.S.; Fitz-Gerald, J.M.; Park, C. Decoupling the effects of crystallinity and orientation on the shear piezoelectricity of polylactic acid. J. Polym. Sci. Part B Polym. Phys. 2011, 49, 1555-1562. [CrossRef]

95. Ando, M.; Takeshima, S.; Ishiura, Y.; Ando, K.; Onishi, O. Piezoelectric antibacterial fabric comprised of polyl-lactic acid yarn. Jpn. J. Appl. Phys. 2017, 56, 10PG01. [CrossRef]

96. Ribeiro, C.; Sencadas, V.; Costa, C.M.; Ribelles, J.L.G.; Lanceros-Méndez, S. Tailoring the morphology and crystallinity of polyL-lactide acid electrospun membranes. Sci. Technol. Adv. Mater. 2011, 12, 15001. [CrossRef]

97. Agrawal, C.M.; Haas, K.F.; Leopold, D.A.; Clark, H.G. Evaluation of polyL-lactic acid as a material for intravascular polymeric stents. Biomaterials 1992, 13, 176-182. [CrossRef]

98. Curry, E.J.; Le, T.T.; Das, R.; Ke, K.; Santorella, E.M.; Paul, D.; Chorsi, M.T.; Tran, K.T.M.; Baroody, J.; Borges, E.R.; et al. Biodegradable nanofiber-based piezoelectric transducer. Proc. Natl. Acad. Sci. USA 2020, 117, 214-220. [CrossRef] [PubMed]

99. Zong, X.; Kim, K.; Fang, D.; Ran, S.; Hsiao, B.S.; Chu, B. Structure and process relationship of electrospun bioabsorbable nanofiber membranes. Polymer 2002, 43, 4403-4412. [CrossRef]

100. Uchio, S. Precision injection molding. Kobunshi 1990, 39, 430-431. [CrossRef]

101. Dubois, J.-C. Ferroelectric Polymers: Chemistry, Physics, and Applications; Nalwa, H.S., Dekker, M., Eds.; Wiley: New York, NY, USA, 1995; Volume XII, p. 895. ISBN 0-8247-9468-0. [CrossRef]

102. Smith, M.; Kar-Narayan, S. Piezoelectric polymers: Theory, challenges and opportunities. Int. Mater. Rev. 2021, 1-24. [CrossRef]

103. Cocca, M.; di Lorenzo, M.L.; Malinconico, M.; Frezza, V. Influence of crystal polymorphism on mechanical and barrier properties of polyl-lactic acid. Eur. Polym. J. 2011, 47, 1073-1080. [CrossRef]

104. Okesola, B.O.; Mata, A. Multicomponent self-assembly as a tool to harness new properties from peptides and proteins in material design. Chem. Soc. Rev. 2018, 47, 3721-3736. [CrossRef]

105. Pan, P.; Zhu, B.; Kai, W.; Dong, T.; Inoue, Y. Polymorphic Transition in Disordered Polyl-lactide Crystals Induced by Annealing at Elevated Temperatures. Macromolecules 2008, 41, 4296-4304. [CrossRef]

106. Sapra, R.; Verma, R.P.; Maurya, G.P.; Dhawan, S.; Babu, J.; Haridas, V. Designer Peptide and Protein Dendrimers: A Cross-Sectional Analysis. Chem. Rev. 2019, 119, 11391-11441. [CrossRef] 
107. Heeley, E.L.; Billimoria, K.; Parsons, N.; Figiel, Ł.; Keating, E.M.; Cafolla, C.T.; Crabb, E.M.; Hughes, D.J. In-situ uniaxial drawing of poly-L-lactic acid PLLA: Following the crystalline morphology development using time-resolved SAXS/WAXS. Polymer 2020, 193, 122353. [CrossRef]

108. Hoogsteen, W.; Postema, A.R.; Pennings, A.J.; Brinke, G.T.; Zugenmaier, P. Crystal structure, conformation and morphology of solution-spun polyL-lactide fibers. Macromolecules 1990, 23, 634-642. [CrossRef]

109. Klug, H.P.; Alexander, L.E. X-Ray Diffraction Procedures: For Polycrystalline and Amorphous Materials, 2nd ed.; John Wiley \& Sons: New York, NY, USA, 1974.

110. Cartier, L.; Okihara, T.; Ikada, Y.; Tsuji, H.; Puiggali, J.; Lotz, B. Epitaxial crystallization and crystalline polymorphism of polylactides. Polymer 2000, 41, 8909-8919. [CrossRef]

111. Huang, S.; Li, H.; Jiang, S. Pressure induced crystallization and in situ simultaneous SAXS/WAXS investigations on structure transitions. CrystEngComm 2020, 22, 4748-4757. [CrossRef]

112. Zhang, Z.; Wang, X.; Wang, Y.; Shen, C.; Liu, C.; Wang, Z. Melt extension-induced shish-kebabs with heterogeneous spatial distribution of crystalline polymorphs in lightly crosslinked polylactic acid. Polymer 2020, 208, 122875. [CrossRef]

113. Di Lorenzo, M.L.; Cocca, M.; Malinconico, M. Crystal polymorphism of polyl-lactic acid and its influence on thermal properties. Thermochim. Acta 2011, 522, 110-117. [CrossRef]

114. Fukada, E. Recent developments of polar piezoelectric polymers. IEEE Trans. Dielectr. Electr. Insul. 2006, 13, 1110-1119. [CrossRef]

115. Sawai, D.; Takahashi, K.; Sasashige, A.; Kanamoto, T.; Hyon, S.-H. Preparation of Oriented $\beta$-Form Polyl-lactic acid by Solid-State Coextrusion: Effect of Extrusion Variables. Macromolecules 2003, 36, 3601-3605. [CrossRef]

116. Alemán, C.; Lotz, B.; Puiggali, J. Crystal Structure of the $\alpha$-Form of Polyl-lactide. Macromolecules 2001, 34, 4795-4801. [CrossRef]

117. Curry, E.J.; Ke, K.; Chorsi, M.T.; Wrobel, K.S.; Miller, A.N.; Patel, A.; Kim, I.; Feng, J.; Yue, L.; Wu, Q.; et al. Biodegradable Piezoelectric Force Sensor. Proc. Natl. Acad. Sci. USA 2018, 115, 909-914. [CrossRef]

118. Shao, J.; Chen, C.; Wang, Y.; Chen, X.; Du, C. Early stage evolution of structure and nanoscale property of nanofibers in thermally induced phase separation process. React. Funct. Polym. 2012, 72, 765-772. [CrossRef]

119. Oh, M.O.; Kim, S.H. Effect of conformation on the properties of uniaxially drawn polylacide films upon drawing temperature. Fibers Polym. 2016, 17, 992-999. [CrossRef]

120. Meaurio, E.; de Arenaza, I.M.; Lizundia, E.; Sarasua, J.R. Analysis of the C=O stretching band of the $\alpha$-crystal of polyL-lactide. Macromolecules 2009, 42, 5717-5727. [CrossRef]

121. Zhang, J.; Duan, Y.; Sato, H.; Tsuji, H.; Noda, I.; Yan, S.; Ozaki, Y. Crystal Modifications and Thermal Behavior of Polyl-lactic acid Revealed by Infrared Spectroscopy. Macromolecules 2005, 38, 8012-8021. [CrossRef]

122. Stoclet, G.; Seguela, R.; Vanmansart, C.; Rochas, C.; Lefebvre, J.-M. WAXS study of the structural reorganization of semi-crystalline polylactide under tensile drawing. Polymer 2012, 53, 519-528. [CrossRef]

123. Jariyasakoolroj, P.; Tashiro, K.; Wang, H.; Yamamoto, H.; Chinsirikul, W.; Kerddonfag, N.; Chirachanchai, S. Isotropically small crystalline lamellae induced by high biaxial-stretching rate as a key microstructure for super-tough polylactide film. Polymer 2015, 68, 234-245. [CrossRef]

124. Jariyasakoolroj, P.; Tashiro, K.; Chinsirikul, W.; Kerddonfag, N.; Chirachanchai, S. Microstructural Analyses of Biaxially Oriented Polylactide/Modified Thermoplastic Starch Film with Drastic Improvement in Toughness. Macromol. Mater. Eng. 2019, 304, 1900340. [CrossRef]

125. Yoshida, T.; Imoto, K.; Tahara, K.; Naka, K.; Uehara, Y.; Kataoka, S.; Date, M.; Fukada, E.; Tajitsu, Y. Piezoelectricity of PolyL-lactic Acid Composite Film with Stereocomplex of PolyL-lactide and PolyD-lactide. Jpn. J. Appl. Phys. 2010, 49, 09MC11. [CrossRef]

126. Farahani, A.; Zarei-Hanzaki, A.; Abedi, H.R.; Haririan, I.; Akrami, M.; Aalipour, Z.; Tayebi, L. An investigation into the polylactic acid texturization through thermomechanical processing and the improved d33 piezoelectric outcome of the fabricated scaffolds. J. Mater. Res. Technol. 2021, 15, 6356-6366. [CrossRef]

127. Chorsi, M.T.; Curry, E.J.; Chorsi, H.T.; Das, R.; Baroody, J.; Purohit, P.K.; Ilies, H.; Nguyen, T.D. Piezoelectric Biomaterials for Sensors and Actuators. Adv. Mater. 2019, 31, 1802084. [CrossRef]

128. Rödel, J.; Webber, K.G.; Dittmer, R.; Jo, W.; Kimura, M.; Damjanovic, D. Transferring lead-free piezoelectric ceramics into application. J. Eur. Ceram. Soc. 2015, 35, 1659-1681. [CrossRef]

129. Liu, F.; Hashim, N.A.; Liu, Y.; Abed, M.R.M.; Li, K. Progress in the production and modification of PVDF membranes. J. Memb. Sci. 2011, 375, 1-27. [CrossRef]

130. Ando, M.; Kawamura, H.; Kitada, H.; Sekimoto, Y.; Inoue, T.; Tajitsu, Y. Pressure-Sensitive Touch Panel Based on Piezoelectric PolyL-lactic acid Film. Jpn. J. Appl. Phys. 2013, 52, 09KD17. [CrossRef]

131. Qaiss, A.; Saidi, H.; Fassi-Fehri, O.; Bousmina, M. Theoretical modeling and experiments on the piezoelectric coefficient in cellular polymer films. Polym. Eng. Sci. 2013, 53, 105-111. [CrossRef]

132. Walton, M.; Cotton, N.J. Long-term in vivo Degradation of Poly-L-lactide PLLA in Bone. J. Biomater. Appl. 2007, $21,395-411$. [CrossRef] [PubMed]

133. Smith, M.; Calahorra, Y.; Jing, Q.; Kar-Narayan, S. Direct observation of shear piezoelectricity in poly-l-lactic acid nanowires. APL Mater. 2017, 5, 74105. [CrossRef]

134. Tokiwa, Y.; Calabia, B.P. Biodegradability and biodegradation of polylactide. Appl. Microbiol. Biotechnol. 2006, 72, $244-251$. [CrossRef] 
135. Tsuji, H.; Ikada, Y. Properties and morphology of polyl-lactide 4. Effects of structural parameters on long-term hydrolysis of polyl-lactide in phosphate-buffered solution. Polym. Degrad. Stab. 2000, 67, 179-189. [CrossRef]

136. Mazzanti, V.; de Luna, M.S.; Pariante, R.; Mollica, F.; Filippone, G. Natural fiber-induced degradation in PLA-hemp biocomposites in the molten state. Compos. Part A Appl. Sci. Manuf. 2020, 137, 105990. [CrossRef]

137. Bergsma, J.E.; de Bruijn, W.C.; Rozema, F.R.; Bos, R.R.M.; Boering, G. Late degradation tissue response to polyl-lactide bone plates and screws. Biomaterials 1995, 16, 25-31. [CrossRef]

138. Nicolini, C. From neural chip and engineered biomolecules to bioelectronic devices: An overview. Biosens. Bioelectron. 1995, 10, 105-127. [CrossRef]

139. Yang, Z.; Zhou, S.; Zu, J.; Inman, D. High-Performance Piezoelectric Energy Harvesters and Their Applications. Joule 2018, 2, 642-697. [CrossRef]

140. Lopes, M.S.; Jardini, A.L.; Filho, R.M. Poly Lactic Acid Production for Tissue Engineering Applications. Procedia Eng. 2012, 42, 1402-1413. [CrossRef]

141. Abdorahim, M.; Rabiee, M.; Alhosseini, S.N.; Tahriri, M.; Yazdanpanah, S.; Alavi, S.H.; Tayebi, L. Nanomaterials-based electrochemical immunosensors for cardiac troponin recognition: An illustrated review. TrAC Trends Anal. Chem. 2016, 82, 337-347. [CrossRef]

142. Cui, H.; Zhao, Q.; Zhang, L.; Du, X. Intelligent Polymer-Based Bioinspired Actuators: From Monofunction to Multifunction. Adv. Intell. Syst. 2020, 2, 2000138. [CrossRef]

143. Koo, J.; MacEwan, M.R.; Kang, S.-K.; Won, S.M.; Stephen, M.; Gamble, P.; Xie, Z.; Yan, Y.; Chen, Y.-Y.; Shin, J.; et al. Wireless bioresorbable electronic system enables sustained nonpharmacological neuroregenerative therapy. Nat. Med. 2018, 24, 1830-1836. [CrossRef]

144. Zhang, A.; Lieber, C.M. Nano-Bioelectronics. Chem. Rev. 2016, 116, 215-257. [CrossRef]

145. Yuk, H.; Lu, B.; Zhao, X. Hydrogel bioelectronics. Chem. Soc. Rev. 2019, 48, 1642-1667. [CrossRef]

146. Guo, Q.; Koo, J.; Xie, Z.; Avila, R.; Yu, X.; Ning, X.; Zhang, H.; Liang, X.; Kim, S.B.; Yan, Y.; et al. A Bioresorbable Magnetically Coupled System for Low-Frequency Wireless Power Transfer. Adv. Funct. Mater. 2019, 29, 1905451. [CrossRef]

147. Boutry, C.M.; Nguyen, A.; Lawal, Q.O.; Chortos, A.; Rondeau-Gagné, S.; Bao, Z. A Sensitive and Biodegradable Pressure Sensor Array for Cardiovascular Monitoring. Adv. Mater. 2015, 27, 6954-6961. [CrossRef]

148. Tajitsu, Y.; Kawai, S.; Kanesaki, M.; Date, M.; Fukada, E. Microactuators with Piezoelectric Polylactic Acid Fibers-Toward the Realization of Tweezers for Biological Cells. Ferroelectrics 2004, 304, 195-200. [CrossRef]

149. Mirfakhrai, T.; Madden, J.D.W.; Baughman, R.H. Polymer artificial muscles. Mater. Today 2007, 10, 30-38. [CrossRef]

150. Mainil-Varlet, P.; Curtis, R.; Gogolewski, S. Effect of in vivo and in vitro degradation on molecular and mechanical properties of various low-molecular-weight polylactides. J. Biomed. Mater. Res. 1997, 36, 360-380. [CrossRef]

151. Briscoe, J.; Dunn, S. Piezoelectric nanogenerators-A review of nanostructured piezoelectric energy harvesters. Nano Energy. 2015, 14, 15-29. [CrossRef]

152. Ribeiro, C.; Costa, C.M.; Correia, D.M.; Nunes-Pereira, J.; Oliveira, J.; Martins, P.; Gonçalves, R.; Cardoso, V.F.; Lanceros-Méndez, S. Electroactive polyvinylidene fluoride-based structures for advanced applications. Nat. Protoc. 2018, 13, 681-704. [CrossRef]

153. Tajitsu, Y. Development of environmentally friendly piezoelectric polymer film actuator having multilayer structure. Jpn. J. Appl. Phys. 2016, 55, 04EA07. [CrossRef]

154. Varga, M.; Morvan, J.; Diorio, N.; Buyuktanir, E.; Harden, J.; West, J.L.; Jákli, A. Direct piezoelectric responses of soft composite fiber mats. Appl. Phys. Lett. 2013, 102, 153903. [CrossRef]

155. Tajbakhsh, S.; Hajiali, F. A comprehensive study on the fabrication and properties of biocomposites of polylactic acid/ceramics for bone tissue engineering. Mater. Sci. Eng. C 2017, 70, 897-912. [CrossRef]

156. Narayanan, G.; Vernekar, V.N.; Kuyinu, E.L.; Laurencin, C.T. Poly lactic acid-based biomaterials for orthopaedic regenerative engineering. Adv. Drug Deliv. Rev. 2016, 107, 247-276. [CrossRef]

157. Kepler, R.G.; Anderson, R.A. Piezoelectricity and pyroelectricity in polyvinylidene fluoride. J. Appl. Phys. 1978, 49, 4490-4494. [CrossRef]

158. Liao, W.-Q.; Zhao, D.; Tang, Y.-Y.; Zhang, Y.; Li, P.-F.; Shi, P.-P.; Chen, X.-G.; You, Y.-M.; Xiong, R.-G. A molecular perovskite solid solution with piezoelectricity stronger than lead zirconate titanate. Science 2019, 363, 1206-1210. [CrossRef] [PubMed]

159. Zhang, H.-Y.; Tang, Y.-Y.; Shi, P.-P.; Xiong, R.-G. Toward the Targeted Design of Molecular Ferroelectrics: Modifying Molecular Symmetries and Homochirality. Acc. Chem. Res. 2019, 52, 1928-1938. [CrossRef] [PubMed]

160. Kawai, H. The Piezoelectricity of Poly vinylidene Fluoride. Jpn. J. Appl. Phys. 1969, 8, 975. [CrossRef]

161. Jia, H.; Li, H.; Lin, B.; Hu, Y.; Peng, L.; Xu, D.; Cheng, X. Fine scale 2-2 connectivity PZT/epoxy piezoelectric fiber composite for high frequency ultrasonic application. Sensors Actuators A Phys. 2021, 324, 112672. [CrossRef]

162. Bafqi, M.S.S.; Latifi, M.; Sadeghi, A.-H.; Bagherzadeh, R. Expected lifetime of fibrous nanogenerator exposed to cyclic compressive pressure. J. Ind. Text. 2020. [CrossRef]

163. Balint, R.; Cassidy, N.J.; Cartmell, S.H. Conductive polymers: Towards a smart biomaterial for tissue engineering. Acta Biomater. 2014, 10, 2341-2353. [CrossRef]

164. Ochiai, T.; Fukada, E. Electromechanical Properties of Poly-L-Lactic Acid. Jpn. J. Appl. Phys. 1998, 37, 3374-3376. [CrossRef]

165. Barroca, N.; Vilarinho, P.M.; Daniel-da-Silva, A.L.; Wu, A.; Fernandes, M.H.; Gruverman, A. Protein adsorption on piezoelectric polyL-lactic acid thin films by scanning probe microscopy. Appl. Phys. Lett. 2011, 98, 133705. [CrossRef] 
166. Fernandes, J.S.; Gentile, P.; Martins, M.; Neves, N.M.; Miller, C.; Crawford, A.; Pires, R.A.; Hatton, P.; Reis, R.L. Reinforcement of poly-l-lactic acid electrospun membranes with strontium borosilicate bioactive glasses for bone tissue engineering. Acta Biomater. 2016, 44, 168-177. [CrossRef]

167. Chinnappan, A.; Baskar, C.; Baskar, S.; Ratheesh, G.; Ramakrishna, S. An overview of electrospun nanofibers and their application in energy storage, sensors and wearable/flexible electronics. J. Mater. Chem. C 2017, 5, 12657-12673. [CrossRef]

168. Müller, C.M.O.; Pires, A.T.N.; Yamashita, F. Characterization of thermoplastic starch/polylactic acid blends obtained by extrusion and thermopressing. J. Braz. Chem. Soc. 2012, 23, 426-434. [CrossRef]

169. Teixeira, E.d.; Curvelo, A.A.S.; Corrêa, A.C.; Marconcini, J.M.; Glenn, G.M.; Mattoso, L.H.C. Properties of thermoplastic starch from cassava bagasse and cassava starch and their blends with poly lactic acid. Ind. Crops Prod. 2012, 37, 61-68. [CrossRef]

170. Suh, T.C.; Amanah, A.Y.; Gluck, J.M. Electrospun Scaffolds and Induced Pluripotent Stem Cell-Derived Cardiomyocytes for Cardiac Tissue Engineering Applications. Bioengineering 2020, 7, 105. [CrossRef]

171. Yang, K.K.; Wang, X.L.; Wang, Y.Z. Progress in nanocomposite of biodegradable polymer. J. Ind. Eng. Chem. 2007, 13, 485-500.

172. Kim, J.K.; Ahn, H. Fabrication and characterization of polystyrene/gold nanoparticle composite nanofibers. Macromol. Res. 2008, 16, 163-168. [CrossRef]

173. Bai, J.; Yang, Q.; Li, M.; Wang, S.; Zhang, C.; Li, Y. Preparation of composite nanofibers containing gold nanoparticles by using polyN-vinylpyrrolidone and $\beta$-cyclodextrin. Mater. Chem. Phys. 2008, 111, 205-208. [CrossRef]

174. Huang, N.F.; Patel, S.; Thakar, R.G.; Wu, J.; Hsiao, B.S.; Chu, B.; Lee, R.J.; Li, S. Myotube Assembly on Nanofibrous and Micropatterned Polymers. Nano Lett. 2006, 6, 537-542. [CrossRef]

175. Bian, W.; Bursac, N. Cellular/Tissue Engineering. Eng. Med. Biol. Mag. IEEE 2008, 27, 109-113. [CrossRef]

176. McKeon-Fischer, K.D.; Freeman, J.W. Characterization of electrospun polyL-lactide and gold nanoparticle composite scaffolds for skeletal muscle tissue engineering. J. Tissue Eng. Regen. Med. 2011, 5, 560-568. [CrossRef]

177. Flaig, F.; Ragot, H.; Simon, A.; Revet, G.; Kitsara, M.; Kitasato, L.; Hébraud, A.; Agbulut, O.; Schlatter, G. Design of Functional Electrospun Scaffolds Based on Polyglycerol sebacate Elastomer and Polylactic acid for Cardiac Tissue Engineering. ACS Biomater. Sci. Eng. 2020, 6, 2388-2400. [CrossRef]

178. Bertuoli, P.T.; Ordoño, J.; Armelin, E.; Pérez-Amodio, S.; Baldissera, A.F.; Ferreira, C.A.; Puiggalí, J.; Engel, E.; del Valle, L.J.; Alemán, C. Electrospun Conducting and Biocompatible Uniaxial and Core-Shell Fibers Having Polylactic acid, Polyethylene glycol, and Polyaniline for Cardiac Tissue Engineering. ACS Omega 2019, 4, 3660-3672. [CrossRef]

179. Cesur, S.; Ulag, S.; Ozak, L.; Gumussoy, A.; Arslan, S.; Yilmaz, B.K.; Ekren, N.; Agirbasli, M.; Kalaskar, D.M.; Gunduz, O. Production and characterization of elastomeric cardiac tissue-like patches for Myocardial Tissue Engineering. Polym. Test. 2020, 90, 106613. [CrossRef]

180. Muniyandi, P.; Palaninathan, V.; Veeranarayanan, S.; Ukai, T.; Maekawa, T.; Hanajiri, T.; Mohamed, M.S. ECM Mimetic Electrospun Porous Poly L-lactic acid PLLA Scaffolds as Potential Substrates for Cardiac Tissue Engineering. Polymers 2020, 12, 451. [CrossRef] [PubMed]

181. Zheng, T.; Yue, Z.; Wallace, G.G.; Du, Y.; Higgins, M.J. Nanoscale piezoelectric effect of biodegradable $\{$ PLA $\}$-based composite fibers by piezoresponse force microscopy. Nanotechnology 2020, 31, 37. [CrossRef] [PubMed]

182. Khan, M.; Xu, Y.; Hua, S.; Johnson, J.; Belevych, A.; Janssen, P.M.L.; Gyorke, S.; Guan, J.; Angelos, M.G. Evaluation of Changes in Morphology and Function of Human Induced Pluripotent Stem Cell Derived Cardiomyocytes HiPSC-CMs Cultured on an Aligned-Nanofiber Cardiac Patch. PLoS ONE 2015, 10, e0126338. [CrossRef] [PubMed]

183. Asiri, A.M.; Marwani, H.M.; Khan, S.B.; Webster, T.J. Greater cardiomyocyte density on aligned compared with random carbon nanofibers in polymer composites. Int. J. Nanomed. 2014, 9, 5533-5539. [CrossRef]

184. Gelmi, A.; Zhang, J.; Cieslar-Pobuda, A.; Ljunngren, M.K.; Los, M.J.; Rafat, M.; Jager, E.W.H. Electroactive 3D materials for cardiac tissue engineering. In Electroactive Polymer Actuators and Devices (EAPAD); Bar-Cohen, Y., Ed.; SPIE: Bellingham, WA, USA, 2015; pp. 445-451. [CrossRef]

185. Gelmi, A.; Cieslar-Pobuda, A.; de Muinck, E.; Los, M.; Rafat, M.; Jager, E.W.H. Direct Mechanical Stimulation of Stem Cells: A Beating Electromechanically Active Scaffold for Cardiac Tissue Engineering. Adv. Healthc. Mater. 2016, 5, 1471-1480. [CrossRef]

186. Hsiao, C.-W.; Bai, M.-Y.; Chang, Y.; Chung, M.-F.; Lee, T.-Y.; Wu, C.-T.; Maiti, B.; Liao, Z.-X.; Li, R.-K.; Sung, H.-W. Electrical coupling of isolated cardiomyocyte clusters grown on aligned conductive nanofibrous meshes for their synchronized beating. Biomaterials 2013, 34, 1063-1072. [CrossRef]

187. Cui, H.; Shao, J.; Wang, Y.; Zhang, P.; Chen, X.; Wei, Y. PLA-PEG-PLA and Its Electroactive Tetraaniline Copolymer as Multiinteractive Injectable Hydrogels for Tissue Engineering. Biomacromolecules 2013, 14, 1904-1912. [CrossRef]

188. Aebischer, P.; Valentini, R.F.; Dario, P.; Domenici, C.; Galletti, P.M. Piezoelectric guidance channels enhance regeneration in the mouse sciatic nerve after axotomy. Brain Res. 1987, 436, 165-168. [CrossRef] 